

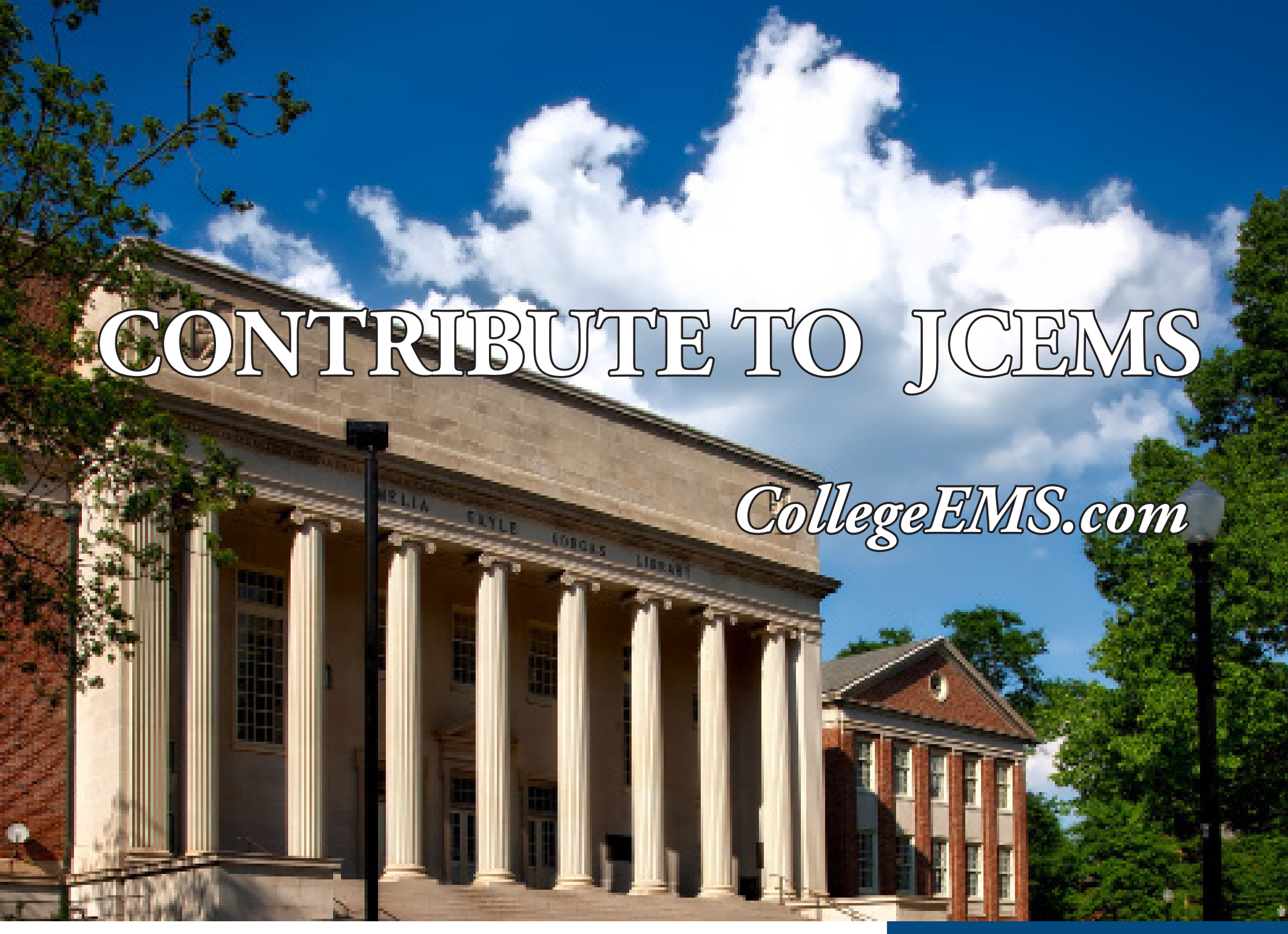

Submit to JCEMS: the official scholarly, peer-reviewed journal of the National Collegiate EMS Foundation.
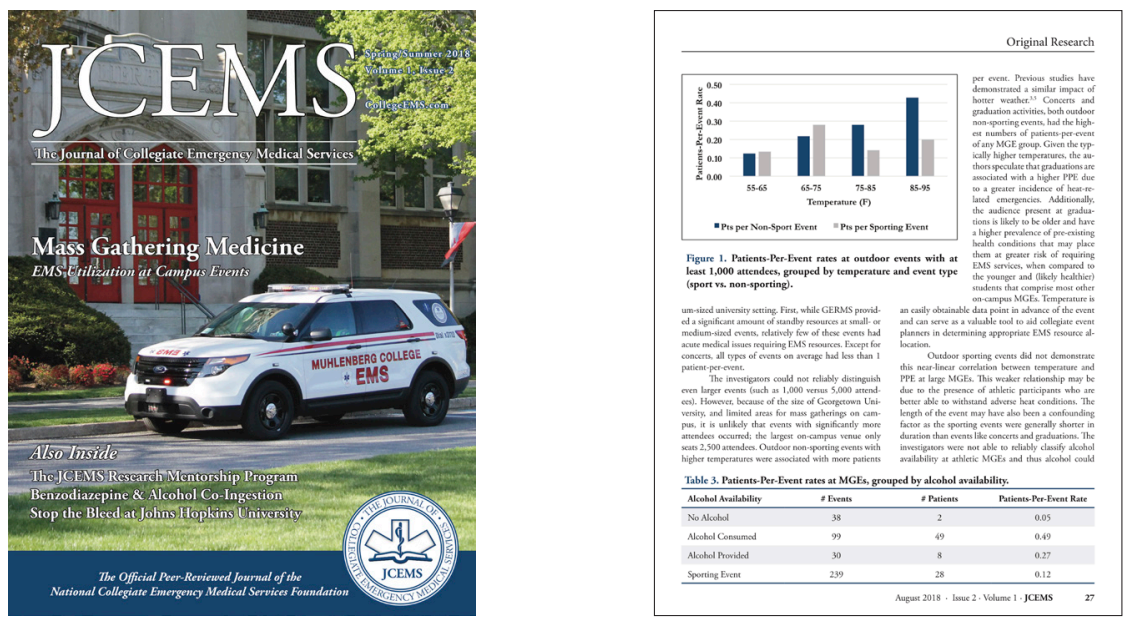

Original research is prioritized. Case reports, reviews, and articles featuring perspectives and commentary are also invited.

\section{Research Mentorship}

We are committed to mentoring student researchers and authors. If you might be interested in conducting a study or submitting a manuscript for publication, consider applying to the JCEMS Research Mentorship Program. Additional details are available at CollegeEMS.com.

\section{Submission Guidelines}

View submission guide at: CollegeEMS.com

Send inquiries to: JCEMS@CollegeEMS.com 


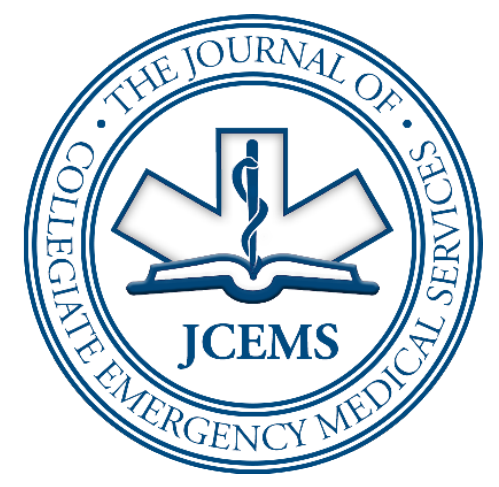

The Journal of

COLLEGIATE EMERGENCY MEDICAL SERVICES

\section{TABLE OF CONTENTS}

\section{The Official Journal of the National Collegiate Emergency Medical Services Foundation}

\section{News \& Commentary}

5 Interview with Virginia Tech Rescue Squad

Winner of the 2019 NCEMSF ALS Skills Classic

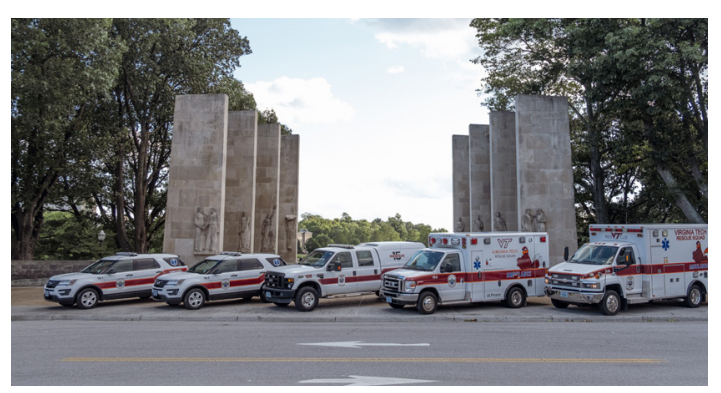

7 Interview with University of Dayton EMS

Winner of the 2019 NCEMSF Collegiate EMS

Celebration of the Week

$9 \quad$ Interview with Lisa Basgall

EMS Director of Rice University EMS

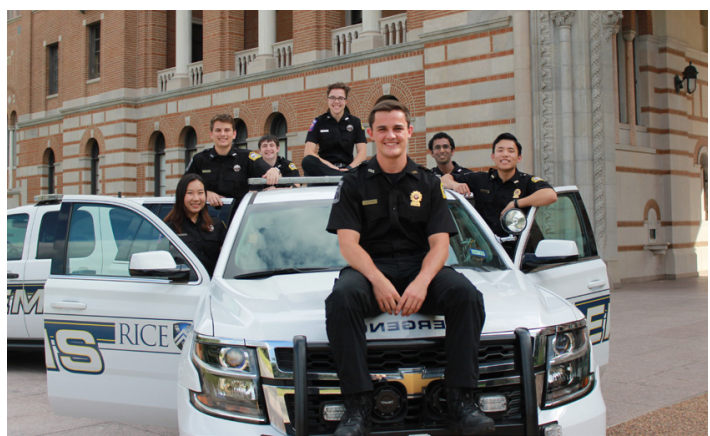

\section{Case Reports}

11 From Volunteer Student Organization to Official Division of a University Department

Tracing the History of Arizona State University

Emergency Medical Services

Jada Wang, NRP, BS, MS

\section{Original Research}

16 Checklists Improve EMS Documentation

Quality Improvement in a Collegiate-Based EMS Agency

Avery S. Alatis, MD; Brian V. Monahan, MD; Allyson D.

Raymond, MD; Korin B. Hudson, MD, CAQ-SM;

Julie T. Vieth, MBChB; Jose V. Nable, MD, NRP

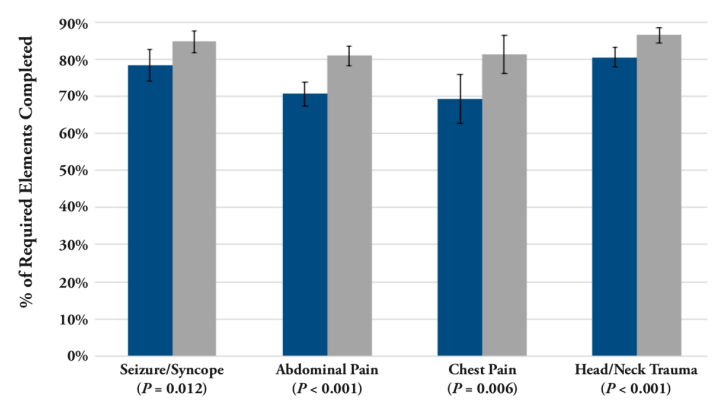

22 Prehospital Antiemetic Therapy in

Campus-Based EMS Settings

A Cross-Sectional Analysis of Statewide EMS Protocols

Carlin C. Chuck, BS, NREMT; Roshini Kalagara, NREMT;

Isabelle Moseley, NREMT; Thomas J. Martin, BA, NRP

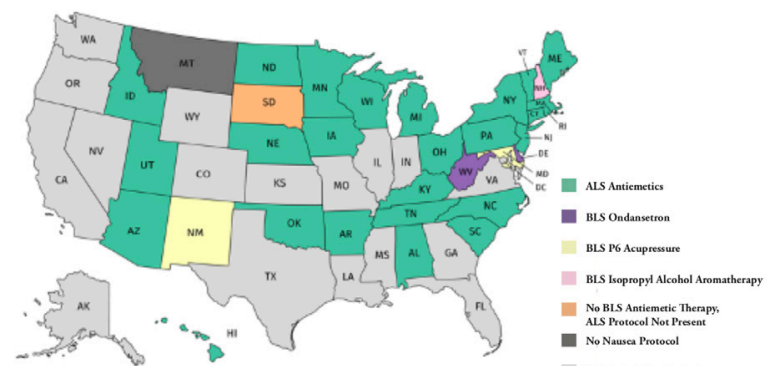

\section{Cover Images}

\section{Front Cover:}

Rice University EMS Providers

Photo Credit: Rice University EMS, Rice University

\section{Back Cover:}

Piers Park, Boston, MA

Photo Credit: Wasin Pummarin (123RF.com) 


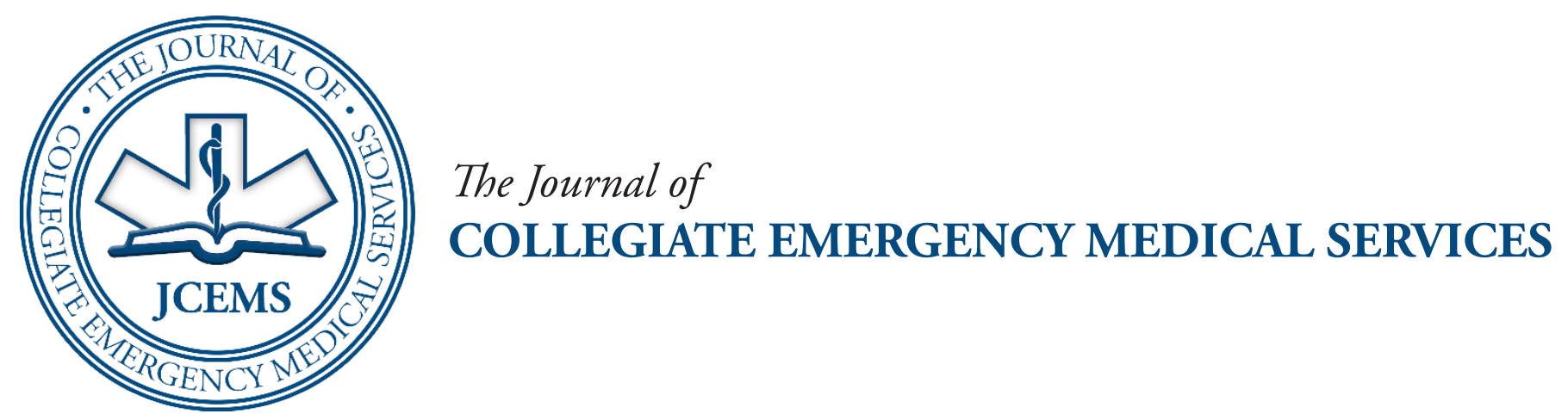

\section{Editors}

Nicholas M.G. Friedman, BA, EMT • Editor-in-Chief

Brittany J. Dingler, MHS, PA-C • Executive Editor

\section{Editorial Board}

Jose Victor L. Nable, MD, MS, NRP

Georgetown University School of Medicine, Washington, DC

Matthew J. Levy, DO, MS, FACEP

The Johns Hopkins University School of Medicine, Baltimore, MD

Benjamin J. Lawner, DO, MS, EMT-P, FACEP

Temple University School of Medicine, Philadelphia, PA

David Goroff, MS, NRP

New Castle County EMS, New Castle, DE

Albert Jagoda, MD

Skidmore College, Saratoga Springs, NY

Brent Campbell, BA, AEMT-CC

Ambulance Service of Fulton County, Gloversville, NY

Patricia Bosen, MSN, FNP-C

Skidmore College, Saratoga Springs, NY

Joseph M. Grover, MD

University of North Caroline School of Medicine, Chapel Hill, NC

Lauren N. Gorstein, BA, EMT-B

Skidmore College, Saratoga Springs, NY

Michael W. Dailey, MD, FACEP, FAEMS

Albany Medical College, Albany, NY

Jeffrey S. Lubin, MD, MPH, FACEP, FAEMS

Penn State College of Medicine, Hershey, PA

Publishing \& Management

Max Moss - Managing Editor

Christopher Gaeta $•$ Director of Business Development

News \& Outreach

Isabel Anzani • Social Media \& Outreach Editor

\section{Special Programs}

Michael Beautyman • Director of Mentorship Program

Joe Caruso • Associate Manager of Special Events

\section{Reviewers}

JCEMS employs a double-blind peer review process for Original Research, Case Reports, and Reviews. The clinical and scientific quality of this publication relies on the rigorous and diligent reviews provided by independent reviewers with subject-matter expertise. JCEMS is grateful for all anonymous independent reviewers who dedicated their time and expertise to the collegiate EMS community.

\section{General Information}

The Journal of Collegiate Emergency Medical Services (JCEMS) [ISSN 25763687] is the official scholarly, peer-reviewed journal of the National Collegiate Emergency Medical Services Foundation. JCEMS is published by the National Collegiate Emergency Medical Services Foundation.

Annual Subscription: Visit https://www.collegeems.com for information on purchasing institutional and personal annual subscriptions.

Reprints: Visit https://www.collegeems.com for information on purchasing reprints and single issues.

Correspondence (Editorial): Address mail to The Journal of Collegiate Emergency Medical Services, National Collegiate Emergency Medical Services Foundation, PO Box 93, West Sand Lake, NY 12196. Email: JCEMS@CollegeEMS.com

Correspondence (Business): Address mail to The Journal of Collegiate Emergency Medical Services, National Collegiate Emergency Medical Services Foundation, PO Box 93,West Sand Lake, NY 12196. Email: JCEMS@CollegeEMS.com

Correspondence (NCEMSF): Address mail to National Collegiate Emergency Medical Services Foundation, PO Box 93,West Sand Lake, NY 12196.

Email: info@ncemsf.org

Copyright: The Journal of Collegiate Emergency Medical Services is an open access publication. Individual authors retain copyright over their own articles. Articles are distributed under the terms of the Creative Commons Attribution 4.0 International (CC BY 4.0) License, which permits unrestricted use, distribution, and reproduction in any medium, provided the original author and source are credited. The full license is available at: https://creativecommons.org/licenses/ by/4.0/. All other content in the journal is copyrighted by the National Collegiate Emergency Medical Services Foundation. All rights reserved.

Online availability: All articles published in print issues of JCEMS are available open access at https://www.collegeems.com. Additional content - not available in print issues - is also published on-line.

Disclaimers: The statements and opinions in articles or other content contained in JCEMS are solely those of the individual authors, contributors, advertisers, and sponsors, and do not represent those of JCEMS, the National Collegiate Emergency Medical Services Foundation, or any representatives, agents, or licensors. The appearance of advertisements does not represent a warranty, endorsement, or approval of the products or services advertised. JCEMS, the National Collegiate Emergency Medical Services Foundation, or any representatives, agents, or licensors make no warranties, representations, or other claims as to the accuracy or completeness of any articles or other content contained in JCEMS. JCEMS and NCEMSF disclaim responsibility for any injury to persons or property resulting from ideas, products, or other content referred to in articles or other content in JCEMS. EMS providers should always consult medical direction and local EMS protocols.

Instructions for Authors: Instructions for authors may be found in the JCEMS Guide for Authors at https://www.collegeems.com. Authors are required to abide by the latest guidelines available on-line at the time of submission. 


\title{
Interview with Virginia Tech Rescue Squad \\ Winner of the 2019 NCEMSF Advanced Life Support Skills Classic
}

\author{
Chief Jake Martin discusses Virginia Tech Rescue Squad's rigorous training program and the squad's \\ unique role as a collegiate-based EMS agency operating at the ALS level.
}

$\mathbf{T}$ he Virginia Tech Rescue Squad (VTRS) is an Advanced Life Support (ALS) ground ambulance service that serves the Blacksburg campus and properties of Virginia Tech. VTRS has won the National Collegiate EMS Foundation (NCEMSF) Skills Classic competition at either the BLS or ALS level for each of the last five years. Their impressive performance reflects the squad's history, leadership, and intense training regimen.

Formed in 1969, VTRS is composed of volunteer undergraduate students and serves all students, staff, faculty, and visitors absolutely free of charge. The VTRS has 43 active members ranging from EMS students to paramedics that fulfill the administrative and operational needs of the rescue squad 365 days every year. The VTRS maintains 3 ALS ambulances, 3 response vehicles, 1 all-terrain vehicle for rural response, a mass casualty trailer, a special operations trailer, a mobile repeater, and equipment for a Cycling Emergency Response Team. The VTRS runs approximately 1,300 emergency calls per year and leads EMS operations for all major athletic and entertainment events.

\section{S}

Congratulations on your success at the NCEMSF Skills Classic. How did your squad address challenges and prepare?

A challenge faced by every team is making sure that the roles and responsibilities are adequately tailored to the competing team. We hold multiple discussions and scenarios for each crew weeks prior to the competition in which our BLS and ALS teams evaluate each other and offer critical feedback. Our teams are constructed randomly most years, although we try to have a member on the team with prior experience at the competition.
Your work at the Skills Classic reflects the fact that your squad has an outstanding overall training program? What makes your training program so successful?

The VTRS on-duty crews train on every single night shift for approximately two hours. These two hours consist of a written lecture style training typically addressing medical conditions, procedures and interventions, operations, team-building exercises, and more as organized by our training officer. After our crews complete this, the crews hold a simulation around campus for a preceptee to test their skills and knowledge. Each year, we fund members to attend multiple conferences, hold annual multi-agency Mass Casualty Simulations, and have mandatory training sessions for our active members. The VTRS has a fantastic culture regarding training and pursuing best practices.

What advice do you have for other teams who are thinking about competing?

It is extremely valuable to participate in the skills competitions at 


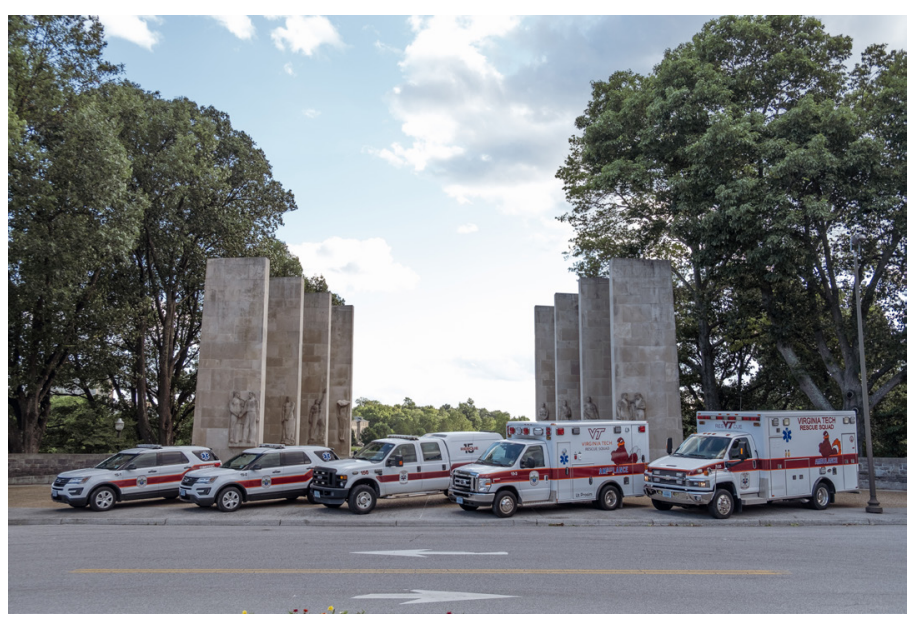

VTRS maintains 3 ALS ambulances, 3 response vehicles, 1 all-terrain vehicle for rural response, a mass casualty trailer, and a special operations trailer.

NCEMSF, regardless of your agency's individual capabilities or experience. The competition is a beneficial way to identify the improvements needed within your agency's training regimen and to strengthen its deficiencies. You may also surprise yourself with your placement.

As an ALS-level agency, VTRS is unique for collegiate EMS organizations. Are there any particular advantages or challenges of being a collegiate EMS squad at the ALS level?

The VTRS sees great benefit in being certified at the ALS level as it allows us to be self-dependent for all incidents. It increases our response capabilities, builds advanced clinical skills, fosters critical thinking and problem solving, and allows our members to continue to strive for more. We pay $100 \%$ tuition for our members to obtain BLS and ALS certifications as it is an investment paid back in service. The largest challenge faced by the VTRS is a fluctuating number of ALS to BLS providers from year to year. We are proud to be able to offer the highest level of care to our community.

Author Affiliations: From Virginia Tech Rescue Squad, Blacksburg, Virginia, USA (J.M.); The Journal of Collegiate Emergency Medical Services, National Collegiate EMS Foundation, West Sand Lake, NY, USA (N.MG.F.)

Address for Correspondence: [Interviewer] Nicholas M.G. Friedman, BA, EMT, The Journal of Collegiate Emergency Medical Services

E-mail: JCEMS@CollegeEMS.com

Conflicts of Interest/Funding Sources: By the JCEMS Submission Declaration Form, all authors are required to disclose all potential conflicts of interest and funding sources. N.MG.F. serves in an uncompensated editorial role for JCEMS. All authors declared that they have no others conflicts of interest. All authors declared that they did not receive funding to conduct the research and/or writing associated with this work.

Submission History: This interview was solicited by the JCEMS Editorial Board Interview responses received December 25, 2019; accepted for publication December 25,2019

Published Online: February 28, 2020

Published in Print: February 28, 2020 (Volume 3: Issue 1)

Reviewer Information: In accordance with JCEMS editorial policy, interview responses are reviewed by the JCEMS Editorial Board. Interviews are published as submitted - save for copy-editing.

Copyright: () 2020 Martin \& Friedman. This is an open access article distributed under the terms of the Creative Commons Attribution 4.0 International (CC BY 4.0) License, which permits unrestricted use, distribution, and reproduction in any medium, provided the original author and source are credited. The full license is available at: https://creativecommons.org/licenses/by/4.0/

Electronic Link: https://doi.org/10.30542/JCEMS.2020.03.01.01

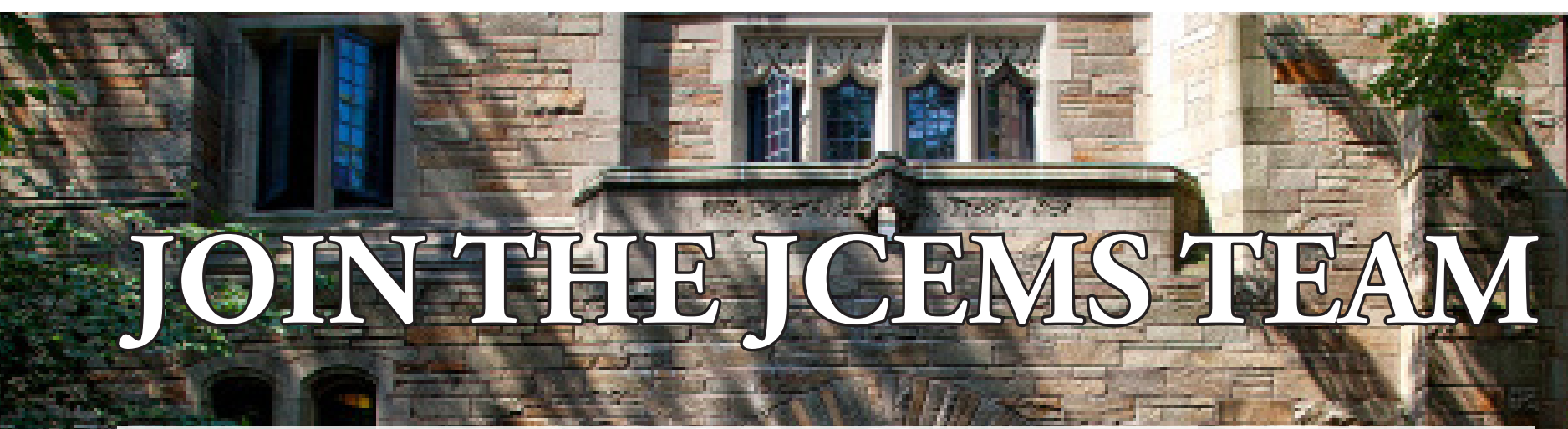

Now seeking motivated, passionate volunteers to join the JCEMS team. Available positions in the design, outreach, editing, and business management departments.

Excellent opportunity for current students and recent alumni to gain professional experience in an innovative start-up publication.

\section{For current opportunities please email JCEMS@CollegeEMS.com or visit:}




\title{
Interview with University of Dayton EMS: \\ Winner of the 2019 NCEMSF Collegiate EMS Week Celebration of the Year
}

\author{
Grace Scharf, the Public Relations Officer of the University of Dayton EMS, shares her agency's \\ tips for organizing a terrific celebration during Collegiate EMS Week.
}

\section{Congratulations on organizing the 2019 Collegiate EMS Week Celebration of the Year! Tell us about the events your squad organized.}

Last year we hosted a variety of events, focusing on outreach and awareness about emergency medicine. Every year we make it a point to host free CPR and First Aid classes for our community. We've noticed that one of the main factors preventing people from becoming certified are the fees behind the process. As a result, we waived those fees for students during National Collegiate EMS week in hopes of reaching a wider audience.

We also hosted table hours, an open house, and a Pie-an-EMT event. With these events we invited the students to meet our members and ask any questions they had regarding our purpose on campus. Our goal is to always make it known that we are EMTs and students should never be afraid to seek help from us. We hoped to make ourselves seem more approachable to the public and more real, rather than just something they hear about in passing or see occasionally on campus. The Pie-an-EMT event also served to raise funds for the Epilepsy Foundation, which has always been very important to UD EMS.

While we kept many of the same events we hosted last year, this Fall we also hosted a blood drive and a takeover at our local Chipotle. Each year we try to host something new as we grow as an organization, and both of these events fit our mission through serving our local community. By sponsoring a blood drive at our university, our members were able to both serve as donors and work the "canteen" where donors went to rest and regain energy after giving blood. Our restaurant takeover raised funds for the Epilepsy Foundation and allowed our alumni to get involved with the celebrations, as many came with their families to support the fundraiser and talk to our current members. This allowed us to expand the scope of our celebration this year to include all members of UD EMS, both past and present.

\section{What makes your events so successful?}

We work to be constantly engaged with our campus and host events that we see a need for in our community. When your community knows who you are as an organization and is able to recognize you on campus, it becomes much easier to create interest in what you are doing and increase attendance at your events. We aim to make our-

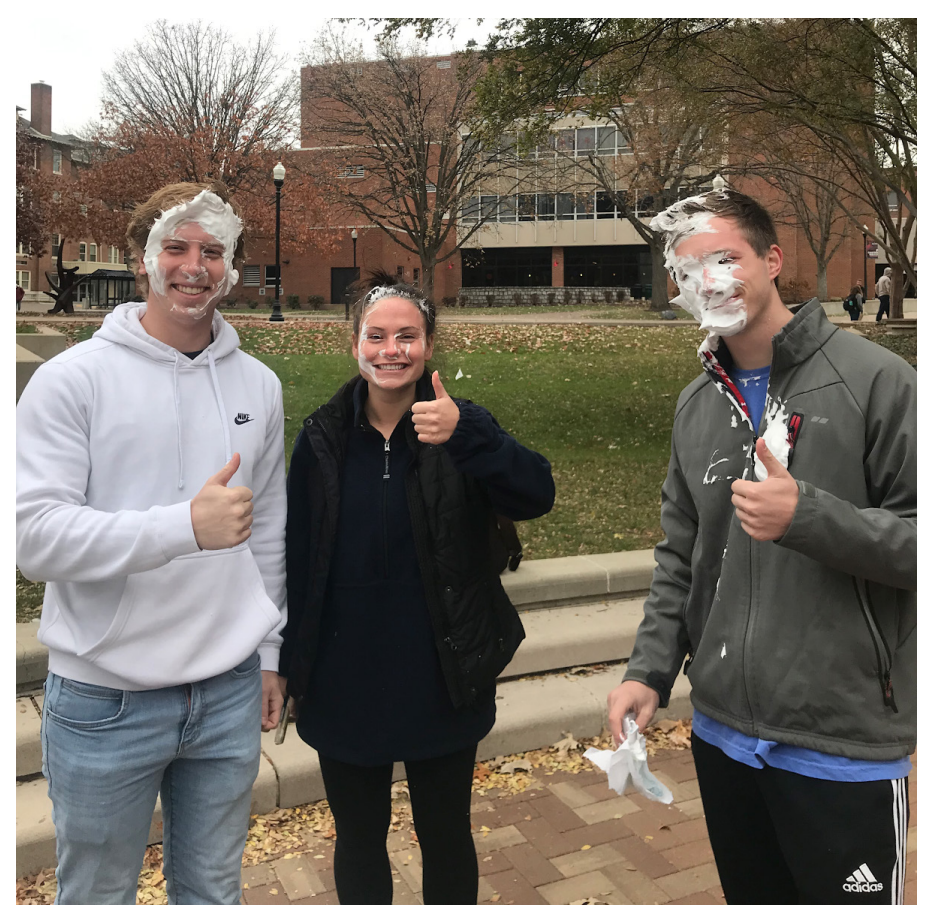

University of Dayton EMS hosts a Pie-an-EMT event each year during Collegiate EMS Week (Dayton, $\mathrm{OH}$ ).

selves known not only through our professional media, but through our members as well. For example, many of our members will post the flyers for our events on their personal social media and talk to other students about what they do as part of our organization.

\section{Why is it important for collegiate EMS organizations to promote Collegiate EMS Week?}

It's important for us to celebrate National Collegiate EMS week to not only raise awareness about collegiate EMS organizations and what they do, but to also celebrate the members of those organizations and everything that has been accomplished throughout the past year. This week is a time to congratulate our peers and reflect on all of their positive impacts on their communities through service as EMTs. Collegiate EMS week promotes bonding between members of our squads and a sense of accomplishment for everyone involved. This celebration is also a perfect way to thank all of the advisors, 
universities, and public safety officials who make collegiate EMS organizations possible.

What advice do you have for collegiate EMS organizations who are planning celebrations for Collegiate EMS Week?

My best piece of advice is to not be afraid to get creative with your events and to try something new. By starting early and engaging with your campus throughout the entire year, gaining interest in your events becomes much easier. You can reach out to the students directly by asking professors if members of your organization can talk to interested students before classes, or reach out to your university to see if they would be able to help you in your celebration by spreading the word about it through emails or social media. Even if your events do not turn out exactly like you planned, they are a great way to learn about what your community seeks from you and how you can expand your scope as a collegiate EMS organization.

Author Affiliations: From University of Dayton Emergency Medical Services, Dayton, OH, USA (L.B.); The Journal of Collegiate Emergency Medical Services, National Collegiate EMS Foundation, West Sand Lake, NY, USA (N.MG.F.).
The Journal of Collegiate Emergency Medical Services E-mail: JCEMS@CollegeEMS.com

Conflicts of Interest/Funding Sources: By the JCEMS Submission Declaration Form, all authors are required to disclose all potential conflicts of interest and funding sources. N.MG.F. serves in an uncompensated editorial role for JCEMS. All authors declared that they have no others conflicts of interest. All authors declared that they did not receive funding to conduct the research and/or writing associated with this work.

Submission History: This interview was solicited by the JCEMS Editorial Board. Interview responses received December 23, 2019; accepted for publication December 24, 2019.

Published Online: February 28, 2020

Published in Print: February 28, 2020 (Volume 3: Issue 1)

Reviewer Information: In accordance with JCEMS editorial policy, interview responses are reviewed by the JCEMS Editorial Board. Interviews are published as submitted - save for copy-editing.

Copyright: (C) 2020 Scharf \& Friedman. This is an open access article distributed under the terms of the Creative Commons Attribution 4.0 International (CC BY 4.0) License, which permits unrestricted use, distribution, and reproduction in any medium, provided the original author and source are credited. The full license is available at: https://creativecommons.org/licenses/by/4.0/

Address for Correspondence: [Interviewer] Nicholas M.G. Friedman, BA, EMT,

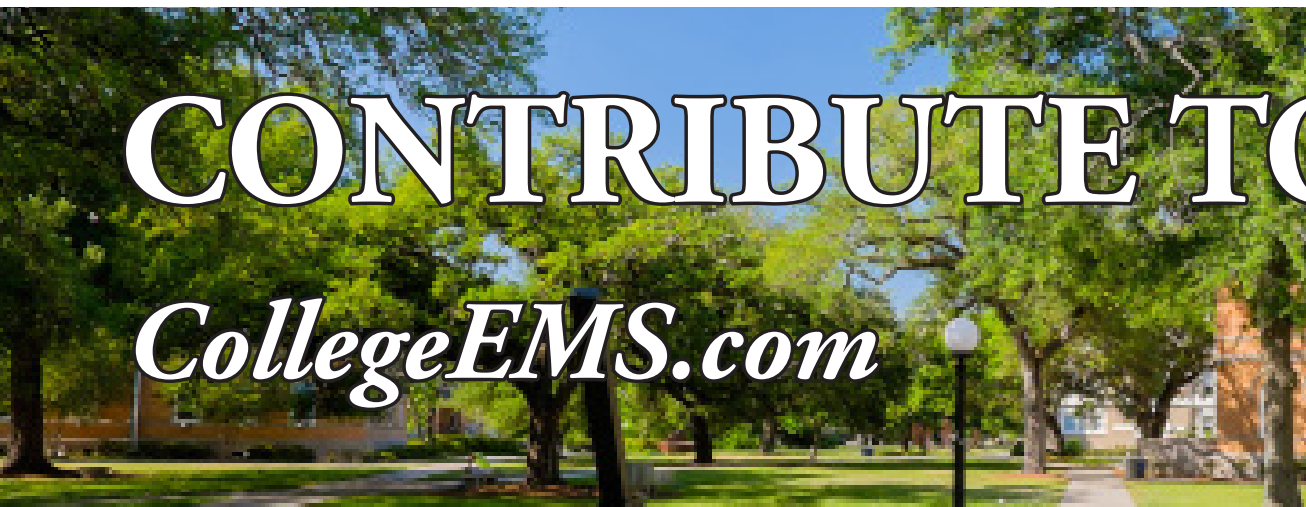

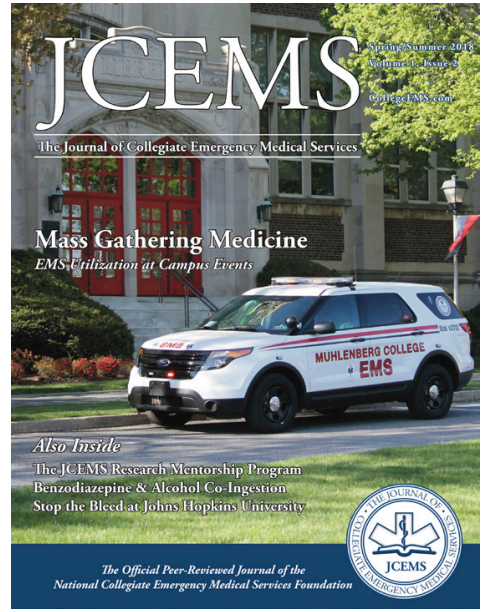

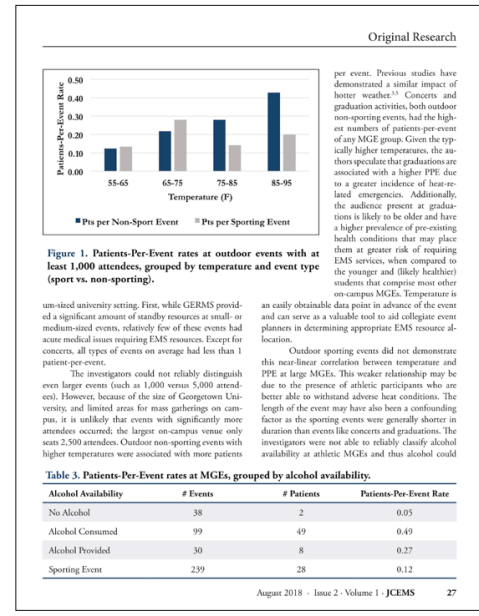

Submit to JCEMS: the official scholarly, peer-reviewed journal of the National Collegiate EMS Foundation.

\section{Research Mentorship}

We are committed to mentoring student researchers and authors. If you might be interested in conducting a study or submitting a manuscript for publication, consider applying to the JCEMS Research Mentorship Program. Additional details are available at CollegeEMS.com.

\section{Submission Guidelines}

View submission guide at: CollegeEMS.com

Send inquiries to: JCEMS@CollegeEMS.com 


\title{
Interview with Lisa Basgall \\ EMS Director of Rice University EMS
}

\begin{abstract}
JCEMS offers an exclusive interview with Lisa Basgall, EMS Director of Rice University EMS - 2019 Collegiate EMS Organization of the Year.
\end{abstract}

$\mathbf{R}$

ice University EMS (REMS) is an advanced life support first responder agency. The agency includes 65 undergraduate volunteers, 25 part time staff (including people who work in EMS full time from around the Houston area, and REMS alumni who are in graduate/medical school and remain in the Houston area), and six physicians on the medical director team. REMS has been serving the Rice community since 1996, and responds to 650-700 calls annually. Additionally, REMS

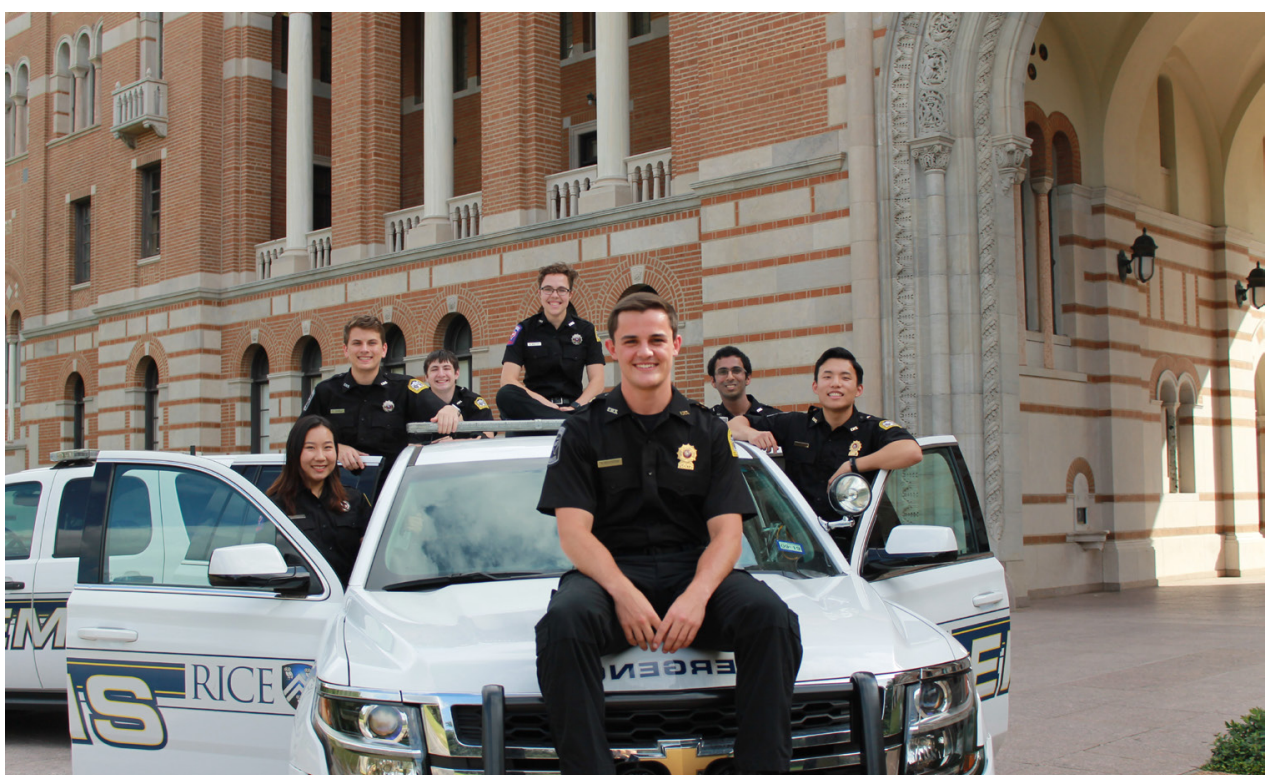

Rice University EMS is composed of 65 undergraduate volunteers, 25 part time staff, and six physician medical directors (Houston, TX). offering EMT and Advanced EMT classes, continuing education courses, and also managing the university's AED program.

\section{$\$$}

Congratulations to you and the REMS team on receiving the 2019 Collegiate EMS Organization of the Year award. What makes REMS so unique and special?

The students that make up a part of REMS, the activities they're involved with, and the accomplishments the team achieves, is what makes REMS stand out. Many college students are involved in varied activities, and pursuing full times studies. Rice students are no exception! I'm always in awe at students that come in as interested volunteers who enroll in EMT class, and within two years they have put in so much time and dedication that they're able to competently serve as leaders of a collegiate EMS agency with a high-stakes mission. Challenges of volunteers regularly joining, creating high-quality simulation training, integrating new personalities into the group, etc, are ongoing. All of this occurs while we're on standby for the next emergency, getting ready for the next class, and preparing for the next community event. Many students dedicate their time to being REMS volunteers, and with the help of committed campus partners, and part time staff, the daily challenges are met with humor and competence!

REMS is fortunate to be supported by full time and part time staff. Tell us about your role.

I have been the EMS Director at Rice for 10 years, and have been a paramedic and EMS educator for 20 years. Before coming to Rice, I had been a paramedic in the 
Philadelphia area for ten years. I taught high school before doing EMS full time, and I maintain my teaching license. As I got more active in EMS, I also worked as a clinical coordinator for the squad where I started in EMS as a volunteer. I became an EMS educator, teaching EMS certification on all levels, and running a continuing education program. I served as an EMS administrator, gaining experience with licensure, billing, and grant writing. All of this varied experience served me well when I took the position at Rice. I am currently the only FTE at Rice EMS. I am a full time staff person, and I also have a faculty appointment as a lecturer.

\section{REMS is an extremely active organization. What re- cent initiatives are you most proud of?}

With the start of this academic year, REMS leadership saw a very full staff roster. There are only so many emergency calls, equipment bags, radios, and golf carts! REMS leadership worked to make a plan to update volunteer applications and training to make the process more selective. Having motivated and interested volunteers is always excellent. Pro-

\section{"Collegiate EMS is an amazing niche of EMS... Teamwork is valued, flexibility is a constant, and serving the community} keeps everyone focused." fessionals from Rice's Human Resources department helped with a workshop on conducting better interviews, and updating application procedures. This project was time-consuming but so help-

ful in developing a new practice to help REMS move forward for the future. The student leadership team, as well as the duty crew members, with input from alumni and the human resources team, worked together to meet the needs of the organization. It's been amazing to see!

\section{What advice do you have for leaders of collegiate EMS} organizations?

Every year it's a little different in where I focus my time and energy as the student leadership changes, but I really enjoy the variety and the different challenges each year work in, as new volunteers are constantly bringing new ideas and energy to the service! Teamwork is valued, flexibility is a constant, and serving the community keeps everyone focused. brings. Collegiate EMS is an amazing niche of EMS to

Author Affiliations: From Rice University Emergency Medical Services, Houston, TX, USA (L.B.); The Journal of Collegiate Emergency Medical Services, National Collegiate EMS Foundation, West Sand Lake, NY, USA (N.MG.F.).

Address for Correspondence: [Interviewer] Nicholas M.G. Friedman, BA, EMT, The Journal of Collegiate Emergency Medical Services

E-mail: JCEMS@CollegeEMS.com

Conflicts of Interest/Funding Sources: By the JCEMS Submission Declaration Form, all authors are required to disclose all potential conflicts of interest and funding sources. N.MG.F. serves in an uncompensated editorial role for JCEMS. All authors declared that they have no others conflicts of interest. All authors declared that they did not receive funding to conduct the research and/or writing associated with this work.

Submission History: This interview was solicited by the JCEMS Editorial Board. Interview responses received January 6, 2020; accepted for publication January 6, 2020.

Published Online: February 28, 2020

Published in Print: February 28, 2020 (Volume 3: Issue 1)

Reviewer Information: In accordance with JCEMS editorial policy, interview responses are reviewed by the JCEMS Editorial Board. Interviews are published as submitted - save for copy-editing.

Copyright: (C) 2020 Basgall \& Friedman. This is an open access article distributed under the terms of the Creative Commons Attribution 4.0 International (CC BY 4.0) License, which permits unrestricted use, distribution, and reproduction in any medium, provided the original author and source are credited. The full license is available at: https://creativecommons.org/licenses/by/4.0/

Electronic Link: https://doi.org/10.30542/JCEMS.2020.03.01.03 


\section{From Volunteer Student Organization to Official Division of a University Department: \\ Tracing the History of Arizona State University Emergency Medical Services}

Jada Wang, NRP, BS, MS

ABSTRACT

Background: Student Emergency Medical Services (SEMS) at Arizona State University (ASU) began as a student-run volunteer organization in 2008. SEMS provided two types of EMS services: 911 Response and Special Event Standby, staffed by volunteer EMTs and volunteer dispatchers. Case Report: In 2016, SEMS leaders formally proposed for SEMS to become a university department under the name ASU EMS. In 2018, ASU EMS became an official division of the ASU Fire Marshal's Office within the ASU Environmental Health and Safety (EHS) Department. SEMS with student volunteers transformed to ASU EMS with paid student workers. This case report traces the history of ASU EMS from 2008 to 2019. Discussion: The transition process from a student volunteer group to an official division of the university with paid workers was time and work intensive. However, the transition ultimately afforded

KEYWORDS: collegiate-based emergency medical services; finance; management

Corresponding Author and Author Affiliations: Listed at the end of this article. numerous benefits to the organization. As opposed to SEMS, ASU EMS has had an easier hiring process, a higher retention rate for student EMS providers, and a consistent $100 \%$ staffing level for shifts. Within the first two semesters of its transition, ASU EMS employed 28 student workers, trained approximately 800 people in CPR, and experienced a 122\% increase in on-campus EMS standby requests and a $128 \%$ increase in gross revenue. Conclusions: Other collegiate EMS leaders and advisors may consider the lessons learned for the development of their collegiate EMS organizations.

$\mathbf{S}$ tudent Emergency Medical Services (SEMS) was founded as an all-student-run volunteer organization at Arizona State University (ASU) in 2008, funded by the undergraduate student government. At that time, the university had over 67,000 enrolled students and four campuses. ${ }^{1}$ Over the next 10 years, SEMS evolved into ASU EMS, an official division of a university department with paid positions for one administrative staff and over 20 student workers. ASU now has a total of 72,709 enrolled students spread among five campuses, located in the cities of Tempe, Phoenix, Glendale, Mesa, and Lake Havasu. ASU EMS operates on all five campuses for Special Event Standby coverage, and operates only on the main campus at Tempe for 911 Response coverage. The Tempe Fire Department (Tempe FD) is required by law to respond to all 911 calls on campus. However, during 911 Response shifts, an ASU EMS team arrives on scene first and initiates care. In instances of low-acuity patients or patients who refuse transport, the Tempe FD often allows ASU EMS to assume full responsibility of the patient and finish providing care on scene. Occasionally, ASU EMS

\footnotetext{
Jada Wang, NRP, BS, MS obtained her Bachelor (2018) and Master (2019) of Science in Biology at Arizona State University (ASU). She joined ASU Emergency Medical Services in 2014 after qualifying as an EMT. Later, as a paramedic, Jada served as the organization's EMS Coordinator. She also completed a vehicular internship with Phoenix (AZ) Fire Department and worked as a paramedic in nearby Scottsdale. She is now an adjunct faculty member for Maricopa Community Colleges.
}

then provides courtesy rides for patients to their dorm rooms, ASU Health Services, or other destinations on campus. ASU EMS is regulated by Arizona Department of Health Services (AZDHS), and all EMT providers are AZDHS-licensed. ASU EMS teams consist of at minimum 2 EMT members, and they carry a full set of equipment as defined by AZDHS. Teams are integrated into the campus 911 dispatch system. ASU EMS team members receive regular continuing education trainings, and all operate under a medical director who is a board-certified emergency medicine physician. ASU EMS is a service that is tailored to the needs of the university and its populations.

This case report details the organization's evolution from a volunteer group to an official division of a university department. Other collegiate EMS leaders and advisors may consider this case report as an example for future desired transitions and development of their collegiate EMS organizations. To understand the history and development of ASU EMS since its establishment in 2008, interviews were conducted with key stakeholders. Subjects included administrative staff who partook in the process of helping SEMS to transition to ASU EMS. In addition to in-person interviews, detailed tracking of internal documents saved in a shared Google Drive folder for SEMS leadership was also completed. The SEMS Google Drive includes documents that cover the entire time range in question, from 2008 to the summer semester of 2018. 


\section{Case Report}

\section{Establishment of Student EMS}

SEMS was originally established to unite young students who were interested in serving their community by providing prehospital emergency care. The process of establishing SEMS was fairly easy to facilitate, as it was categorized as a student organization. The only requirements in this process were to recruit volunteer members and to find an advisor for the organization. Dr. Stefanie Schroeder, a board-certified emergency medicine physician and Chief of Medical Staff at ASU Health Services, agreed to serve as the Medical Director and official advisor to SEMS. She has remained a supporter and promoter for the organization ever since, and she is the Medical Director for ASU EMS to this day.

When SEMS founders first sought to establish and structure the
This was due primarily to Dr. Schroeder's dual roles as Medical Director for SEMS and Chief of Medical Staff at ASU Health Services. For example, Dr. Schroeder played a critical role in drafting and approving medical protocols for SEMS based on national EMS standards. Additionally, Dr. Schroeder facilitated the establishment of SEMS' jurisdiction. In Arizona, EMS systems are fire-based, and the main campus at Tempe was under the jurisdiction of the Tempe Fire Department (Tempe FD). Therefore, conflicts emerged when firefighters expressed discomfort with college-aged EMTs responding to 911 calls. Dr. Schroeder advocated for SEMS in the face of this pushback and initiated meetings between Tempe FD chiefs and SEMS leaders to resolve these conflicts.

\section{Financial Sustainability}

SEMS received minimal pushback from the university due to its

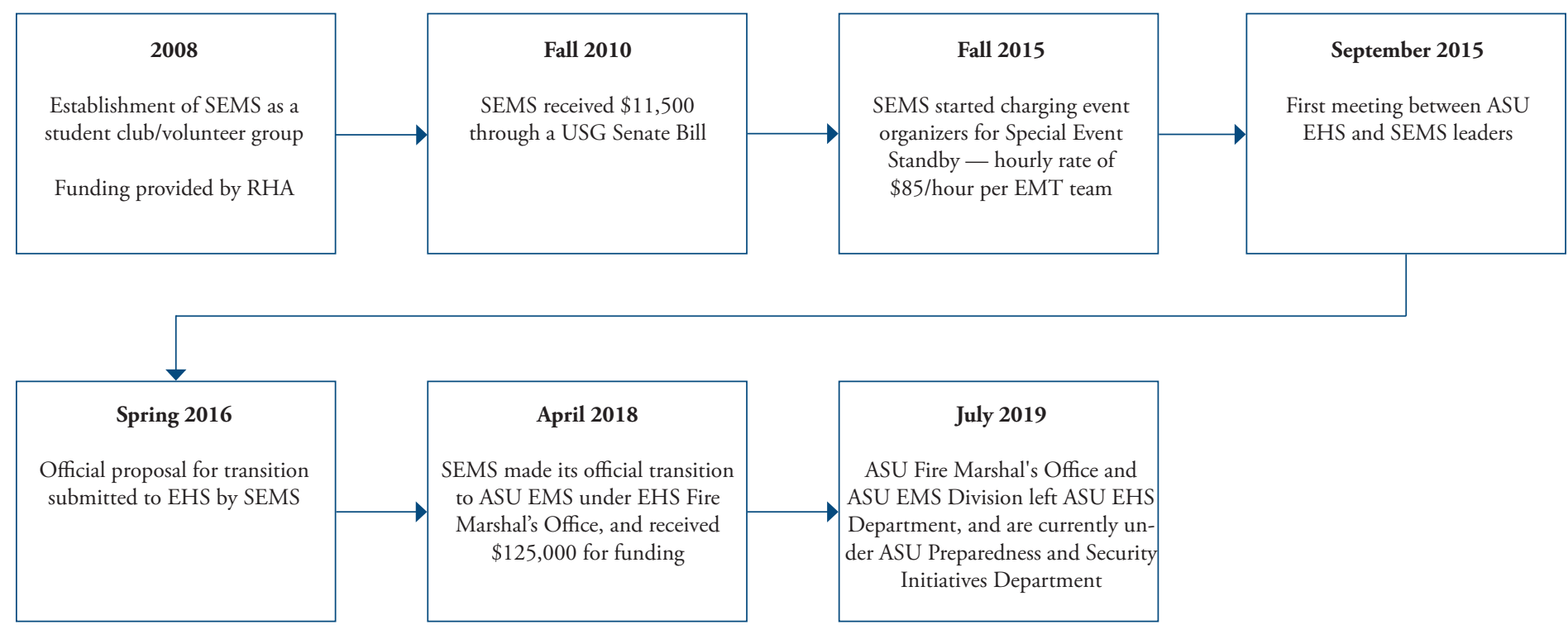

Figure 1. Important milestones in the transition process from Student EMS (SEMS) to ASU EMS.

organization in 2008, the ASU administration offered the founders the opportunity to become an official division under their Health Services department (Figure 1). However, if SEMS were taken under ASU Health Services, their EMTs and paramedics would have had a severely limited scope of practice due to liability concerns. ASU Health Services expressed a belief that SEMS was at higher risk of malpractice due to the young age and lack of experience of collegiate EMTs. This limited scope of practice would not have included the administration of medications such as oxygen or oral glucose, and would have afforded SEMS providers limited authority to make independent medical decisions. To avoid limiting the potential of the organization, the founders opted instead to establish themselves as a volunteer group outside of any university department. As an independent group of volunteers, SEMS members were able to utilize their full scope of practice.

Although SEMS did not become an official division of ASU Health Services, the two organizations maintained a close relationship and SEMS received considerable guidance and support from the Health Services department during early phases of development. status as a student organization, and because many event organizers on campus appreciated having EMS services on standby. SEMS was able to receive funding as a student organization and a 501(c) (3) non-profit organization. Initial funding for SEMS was provided entirely by the ASU Residence Hall Association (RHA). Within one year of its inception, SEMS began receiving some money from the ASU Undergraduate Student Government (USG) Appropriation process. In Fall 2010, SEMS received \$11,500 through a USG Senate Bill (Figure 1). RHA started slowly decreasing financial support for SEMS in Fall 2010 and discontinued all support in 2012. USG funding for SEMS never exceeded over $\$ 10,000$ per year, and typically remained between $\$ 5,000$ to $\$ 8,500$. SEMS also received donations from the Panhellenic Council and ASU Sun Devil Athletics. SEMS originally provided EMS coverage for special events on ASU campuses free of charge. However, to make the organization more financially self-sustaining, SEMS leadership decided in Fall 2015 to charge an hourly rate for special event coverage of $\$ 85 /$ hour per team consisting of 2 EMTs (Figure 1). ASU EMS office space located in McClintock Residence Hall is still provided free of charge 


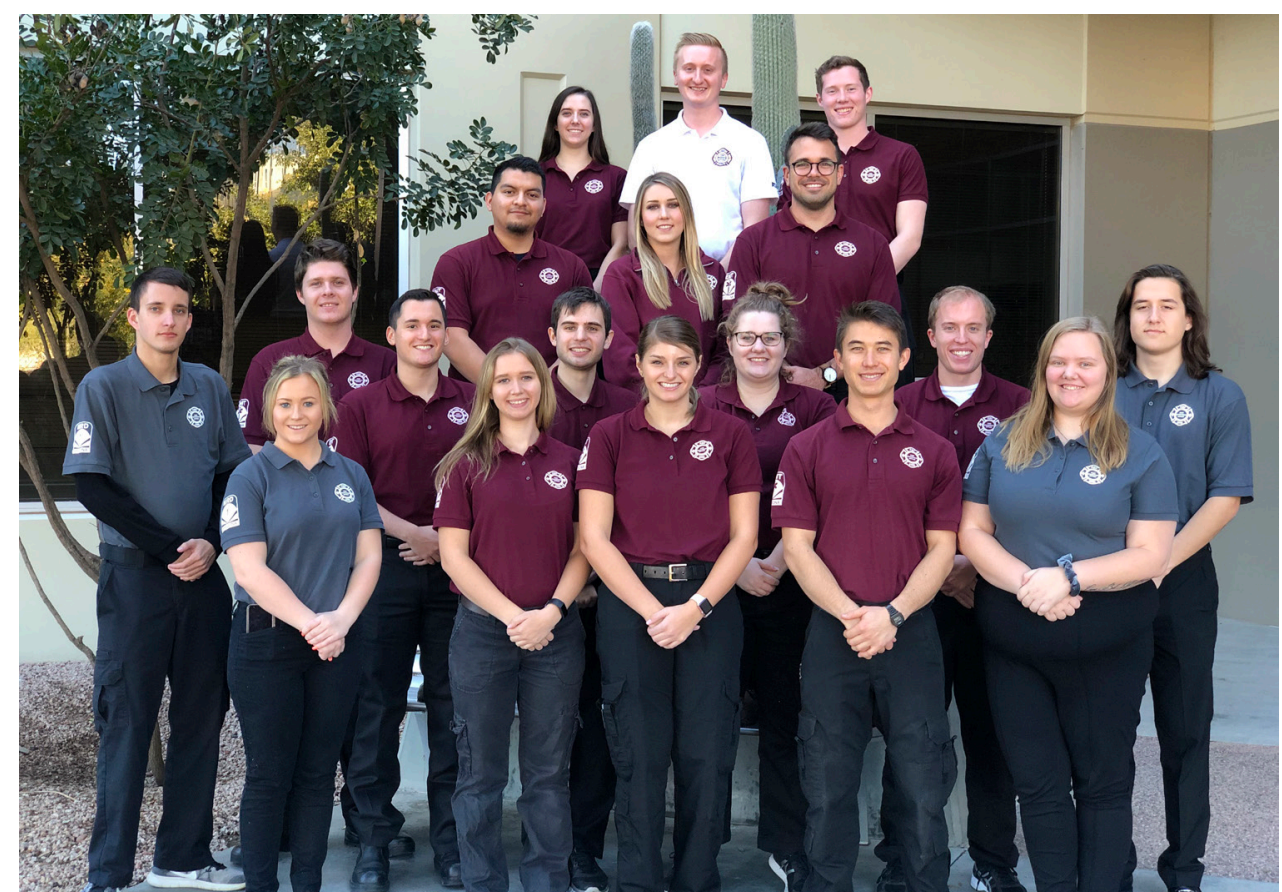

ASU EMS team during Fall 2019 pre-semester training. This is the first group of student workers hired by ASU EMS after its official transition. standby requests. Many special events prior to the year 2015 were handled through email, phone calls, or face-to-face interactions, and were not logged. However, SEMS was ultimately successful in making the case that SEMS' services were needed on campus, and that demand was increasing over time.

During these early meetings, the vision of the main stakeholders was to restructure SEMS as a professional service center similar to ASU Health Services, under the name ASU EMS with volunteer EMTs and dispatchers as well as a part-time paid administrator. The stakeholders anticipated that it would be easier for SEMS to transition if there was only one paid staff position, since a smaller budget would be required from the university. All stakeholders agreed that a primary goal in this transition was for ASU EMS to eventually be self-funded. Therefore, stakeholders decided to keep constant the original rate of $\$ 85 /$ hour per team for Special Event Standby requests so as to maintain the network SEMS had formed with event organizers and other university departments. Additionally, the ASU Fire Marshal proposed a policy which would limit ASU organizers' ability to hire outside EMS/first aid groups. In theory, this policy would encourage utilization of ASU EMS services on campus, increasing gross revenues. In addition, this policy would reduce costs for the university, as SEMS event standby coverage rates for a two-member team were substantially lower than local competitors (Table 1).

\section{Proposal Development and Iterations}

Over the course of several months, stakeholders continued to develop their vision for ASU EMS. By the time the final proposal was submitted to ASU, three large changes had been made. First, the paid administrative staff position would be full-time, not parttime, under the title of EMS Coordinator. The EMS Coordinator would oversee personnel, finance, logistics, operations, and outreach for ASU EMS. SEMS leaders and EHS agreed that a full-time staff member was needed to initiate and lead a newly formed university EMS organization. Second, student EMS providers would be paid workers as opposed to volunteers. Student workers would receive an hourly wage determined by their ranking in the organization. SEMS leaders and EHS believed this would increase retention of student workers as well as the organization's capacity to staff 911 Response and Special Event Standby shifts. Finally, the proposal did not include a policy limiting on-campus hiring of off-campus EMS/ first aid group as stakeholders agreed that it would not be feasible for ASU EHS to implement.

In early 2016, the Business Operations Manager at EHS and ASU's Director of Business Applications and Fiscal Control met with ASU Financial Services and passed along the final written proposal (Figure 1). This proposal justified the need for initial funding from ASU, explained why a paid administrator was essential for the success of the organization, and demonstrated how ASU EMS would 
Table 1. Examples of Arizona EMS agencies and associated costs for event standby coverages with two providers. ${ }^{2}$

\begin{tabular}{lcccc}
\hline Agency Name & Type of Agency & Type of Entity & Staffing Level & Standby Rate \\
\hline ABC Ambulance & Independent & For Profit & 1 Paramedic, 1 EMT & $\$ 158.65 / \mathrm{hr}$ \\
$\begin{array}{l}\text { American Medical Response of } \\
\text { Maricopa }\end{array}$ & Independent & For Profit & 1 Paramedic, 1 EMT & $\$ 206.70 / \mathrm{hr}$ \\
LifeLine Ambulance Service & Independent & For Profit & 1 Paramedic, 1 EMT & $\$ 163.20 / \mathrm{hr}$ \\
Ajo Ambulance & Independent & Nonprofit & 1 Paramedic, 1 EMT & $\$ 433.47 / \mathrm{hr}$ \\
Tempe Fire Department & Fire Department & Municipality & 1 Paramedic, 1 EMT & $\$ 206.70 / \mathrm{hr}$ \\
\hline
\end{tabular}

eventually become self-funded. To effectively make this case, SEMS collected data on its operations and finances and made predictions for volunteer hours and revenue return for subsequent fiscal years.

The proposal for the official transition from SEMS to ASU EMS took almost 3 years to move through the necessary process (Figure 1). During this wait period, there was limited information provided to SEMS leaders from the university. SEMS leaders regularly reached out to EHS asking for updates and were instructed to keep waiting throughout the transition period. Ultimately, however, the proposal was approved with minimal modifications.

\section{Official Transition to University Department}

On April 1, 2018, SEMS officially made its transition to ASU EMS under the EHS Fire Marshal's Office and received \$125,000 of funding from the office of the Chief Financial Officer for the fiscal year of 2018-19 (Figure 1). This budget was intended to hire an EMS Coordinator and several student worker staff as well as to purchase necessary equipment and supplies. Soon after the transition, the EMS Coordinator and ASU Assistant Fire Marshal conducted interviews to hire student EMS workers. The majority of the initial applicants had previously volunteered with SEMS. Prior to the transition, SEMS had over 40 volunteer EMTs and dispatchers. Post-transition, ASU EMS maintained a size of approximately 20 student workers, although this size has fluctuated depending on student schedules and school workload. In total, 28 student workers have been employed since the transition. The process of hiring student workers was found to be easier than recruiting student volunteers. Additionally, the post-transition retention rate has been higher and student workers have tended to work more shifts than volunteers. Therefore, despite a decrease in the overall roster of the organization, ASU EMS has managed to staff Special Event Standby and 911 Response shifts at higher levels and more consistently.

In July 2019, the Fire Marshal's Office and ASU EMS left the EHS Department and relocated under the Preparedness and Security Initiatives Department. This transfer has not notably impacted ASU EMS, as it remains a division of the Fire Marshal's Office and all operations remain the same.

\section{Discussion}

The transition from SEMS to ASU EMS was long, hard, complicated, and required many individuals lending support. The process was particularly stressful and demoralizing for student EMS leaders, who underwent years of effort to achieve a result that, for many, did not arrive during their time on campus. Additionally, throughout the transition period, many major decisions were out of the student leaders' hands, and they were provided limited updates and information. Despite these barriers, the success of this process has led to numerous benefits for the organization. By housing ASU EMS within an official university department and compensating student EMS providers, the organization has increased the quantity of its services, diversified its role on campus, and promoted its own financial wellbeing.

Prior to the transition, SEMS leaders occasionally canceled 911 Response shifts or denied requests for EMS standby at events. This was primarily due to staffing shortages as a result of conflicts with members' school and work schedules. Now that ASU EMS compensates its student workers with an hourly wage, many student EMS providers rely on this income in place of other jobs. Fewer work-related schedule conflicts have largely eliminated staffing shortages for ASU EMS. As a result, the organization has expanded its capacity to consistently staff 911 response shifts on Friday and Saturday nights, and has maintained 100\% staffing level for all 911 Response and Special Event Standby shifts.

Since the transition, ASU EMS has received a steadily increasing number of Special Event Standby requests. While ASU EMS is currently unable to release specific financial information such as gross revenue or wages, the organization continues to receive an annual budget from the university for each fiscal year. The original vision for ASU EMS to be self-funded remains unchanged. ASU EMS aims to eventually generate more revenue through special event coverage than their annual budget, in which case it would no longer require university funding.

Being an official university organization has allowed ASU EMS to expand its functions due to increased funding levels and advocacy on its behalf from a parent department. For example, ASU EMS is now tasked with routinely inspecting automated external debrillators (AEDs) on all ASU campuses. Additionally, ASU EMS has implemented a series of classes to the ASU community on CPR, bleeding control, and opioid awareness and response. Since the transition, approximately 800 people have been trained in CPR on campus. By offering these classes, ASU EMS generates additional revenue, promotes overall campus health, and advertises ASU EMS to the campus community. 
Prior to the transition, SEMS received occasional pushback or disapproval from the Tempe FD due to concerns about student-aged EMTs responding to 911 medical calls. Legitimizing ASU EMS as an official division within the university has strengthened the relationship between student EMTs and the Tempe FD. Since the transition, the EMS Coordinator has started meeting regularly with Tempe FD Deputy Chiefs and Captains. EMT supervisors have also pushed for more ride-alongs and visits to the FD stations. Due to a resulting higher level of comfort and familiarity with student EMTs, as well as more consistent staffing levels, ASU EMS has increased its 911 call volume with Tempe FD. The Tempe FD has started seeing ASU EMS as an asset instead of a liability.

For students at universities who are considering starting a collegiate-based EMS (CBEMS) organization, or for existing volunteer-based CBEMS organizations considering transitioning to an official division within a university department, it is important to remember to be persistent, patient, and determined. When considering becoming an official division, office, or department, organizations should carefully think about to which university 'parent' department the CBEMS organization would best belong. Organizations should then reach out to the department leaders and present why the proposed change would benefit the department, university, and larger campus community. In order to make this case effectively, CBEMS organizations should gather data that demonstrate the need for EMS coverage on campus, such as number of students, staff, and daily visitors, and number of EMS calls on campus. It is also important to demonstrate how establishing an EMS program on campus would be financially feasible for the university and how revenue would be generated. If possible, showing how a CBEMS organization could alleviate on-campus call volumes from local fire or EMS departments would also be beneficial. Beyond demonstrating need, critical to this process is finding a department leader or advisor who believes in the mission of the CBEMS organization and is willing to be an advocate for the organization. Receiving funding from the university financial office is especially challenging in the absence of an administrative advocate for the organization.

\section{Conclusions}

From a student organization to an official division of a university department, the transition process for ASU EMS was time-consuming. However, ASU EMS finally received the budget to be funded as an official division under a university department in 2018. ASU EMS now works alongside the ASU Fire Marshal's Office, the Preparedness and Security Initiatives Department, ASU Health Services, and the Tempe Fire Department. ASU EMS continues to have a steady increase in requests for EMS standby coverage and other campus services such as AED inspections and CPR classes. In place of other part-time employment, student EMTs can work for the ASU community doing something they love while putting their skills, certifications, and training to use. Since the transition, there has been a constant 100\% staffing level for 911 Response and Special Events Standby shifts. ASU EMS has also seen an increase in gross revenue, with the ultimate goal to be self-funded. By working shifts and offering courses across campus, the organization is promoting the ASU Fire Marshal's Office and the EMS program to the ASU community. There are also better working relationships among ASU departments with better coordination. Ultimately, despite a long and laborious process, ASU EMS has transformed for the better.

\section{Acknowledgments}

I would like to acknowledge my thesis advisors from Arizona State University (ASU) - Dr. Matt Chew, Dr. Jane Maienschein, Dr. Karin Ellison, and Dr. Alison Essary.

I thank them for their assistance with my research and writing, and their unfailing support and encouragements. I would like to acknowledge the Center for Biology and Society at ASU, and the ASU Fire Marshal's Office.

\section{References}

1. Arizona State University. Enrollment Trends - Metropolitan Campuses. https://facts.asu.edu/Pages/Enrollments/Enrollment Trends.aspx. Accessed December 2019.

2. Arizona Department of Health Services, Bureau of Emergency Medical Services and Trauma System. Arizona Ground Ambulance Service Rate Schedule. https://www.azdhs.gov/documents/preparedness/emergencymedical-services-trauma-system/ambulance/ground/rates/2018/groundambulance-rates-jan-2018.pdf. Published January 8, 2018. Accessed December 2019.

Author Affiliations: From Center for Biology \& Society, Arizona State University School of Life Sciences and Emergency Medical Services, Arizona State University Fire Marshal's Office - both in Tempe, AZ, USA (J.W.).

Address for Correspondence: Jada Wang, NRP, BS, MS.

E-mail: Jada.Wang@asu.edu

Conflicts of Interest/Funding Sources: By the JCEMS Submission Declaration Form, all authors are required to disclose all potential conflicts of interest and funding sources. All authors declared that they have no conflicts of interest. All authors declared that they did not receive funding to conduct the research and/or writing associated with this work.

Authorship Criteria: By the JCEMS Submission Declaration Form, all authors are required to attest to meeting the four ICMJE.org authorship criteria: (1) Substantial contributions to the conception or design of the work; or the acquisition, analysis, or interpretation of data for the work; AND (2) Drafting the work or revising it critically for important intellectual content; AND (3) Final approval of the version to be published; AND (4) Agreement to be accountable for all aspects of the work in ensuring that questions related to the accuracy or integrity of any part of the work are appropriately investigated and resolved.

Prior Publication: Information from this case report was included in an unpublished Master's Thesis: Wang J. Investigating the Current Status of Collegiate Emergency Medical Services (EMS) Organizations via a National Survey Study and Tracing the History of Arizona State University EMS Department [Unpublished master thesis]. Tempe, AZ: Arizona State University. 2019.

Submission History: Received December 27, 2019; accepted for publication February $19,2020$.

Published Online: February 28, 2020

Published in Print: February 28, 2020 (Volume 3: Issue 1)

Reviewer Information: In accordance with JCEMS editorial policy, Case Report manuscripts undergo double-blind peer-review by at least two independent reviewers. JCEMS thanks the anonymous reviewers who contributed to the review of this work.

Copyright: () 2020 Wang. This is an open access article distributed under the terms of the Creative Commons Attribution 4.0 International (CC BY 4.0) License, which permits unrestricted use, distribution, and reproduction in any medium, provided the original author and source are credited. The full license is available at: https:// creativecommons.org/licenses/by/4.0/

Electronic Link: https://doi.org/10.30542/JCEMS.2020.03.01.04 


\title{
Checklists Improve EMS Documentation:
}

\section{Quality Improvement in a Collegiate-Based EMS Agency}

\author{
Avery S. Alatis, MD; Brian V. Monahan, MD; Allyson D. Raymond, MD; Korin B. Hudson, MD, CAQ-SM; \\ Julie T. Vieth, MBChB; Jose V. Nable, MD, NRP
}

\begin{abstract}
Background: Ensuring accurate and complete emergency medical services (EMS) patient documentation is vital for the safe transition of patient care. Objectives: This study examined whether a quality improvement (QI) project focused on documentation via checklists can improve the inclusion of key documentation criteria on electronic patient care reports (ePCRs) in a collegiate-based EMS system. Methods: This retrospective study analyzed the ePCRs of Georgetown Emergency Response Medical Services before and after the revision of documentation checklists as part of the agency's continuous QI process. Reports for calls in which patients presented with any of the following chief complaints were analyzed: chest pain, abdominal pain, seizure/syncope, and head/neck trauma. Results were reported as the percentage of required elements noted in the checklists that were documented. Results: Over a 2-year period (20132015), 373 charts were analyzed. Following the adoption of the updated documentation checklists, there were statistically significant increases in the overall inclusion of required documentation elements for all studied chief complaints: chest pain (69.29\% to $81.31 \%)$; abdominal pain $(70.65 \%$ to $80.82 \%)$, head trauma (80.47\% to $86.39 \%)$; seizure/syncope (78.3\% to $84.67 \%)$; all $\mathrm{p}<0.05$. Conclusions: Checklists are a potential tool to improve EMS documentation as part of an agency's continuous QI process in a collegiate-based EMS setting.
\end{abstract}

KEYWORDS: collegiate-based emergency medical services; checklist; documentation; quality improvement

Corresponding Author and Author Affiliations: Listed at the end of this article.
A ccurate, complete, and reliable EMS documentation is important for effective communication and the safe transition of patient care. ${ }^{1}$ Inadequate prehospital documentation has been associated with increased in-hospital morbidity and mortality. ${ }^{2}$ Prehospital care reports are valuable tools to assess and improve the quality of care. Proper documentation enables EMS agencies to collect and trend data to maximize operational performance, focus training and continued education efforts, provide membership feedback, and adjust medical protocols. Quality improvement (QI) strategies have been shown to enhance EMS performance and documentation. ${ }^{3}$ For collegiate-based EMS (CBEMS) organizations, confronted with rapid membership turnover and smaller call vol-

Avery S. Alatis, MD is an emergency medicine (EM) resident physician at Georgetown/MedStar Washington Hospital Center, assistant medical director for Georgetown Emergency Response Medical Services (GERMS), and previously served GERMS as a crew chief and vice president for education. Brian V. Monahan, MD is a general surgery resident physician at Temple University and previously served GERMS as a crew chief and captain. Allyson D. Raymond, MD is an EM resident physician at Temple University and previously served GERMS as a crew chief and vice president for education. Korin B. Hudson, MD, CAQ-SM is an associate professor of EM at Georgetown University School of Medicine and MedStar Georgetown University Hospital and has previously served as medical director for GERMS. Julie T. Vieth, $\mathrm{MBChB}$ is the director of education for EM and interim chair of the Emergency Department at Canton-Potsdam Hospital and has previously served as medical director for GERMS. Jose V. Nable, MD, NRP is an assistant professor of EM at Georgetown University School of Medicine and MedStar Georgetown University Hospital, in addition to serving as medical director for GERMS. umes, QI review processes may be especially critical in ensuring adequate documentation.

The Georgetown Emergency Response Medical Service (GERMS) is a basic life support (BLS) CBEMS agency in Washington, DC that serves Georgetown University and the surrounding community. GERMS is composed entirely of undergraduate student volunteers and responds to approximately 900 EMS calls annually. In 2014, a longstanding set of documentation checklists to assist providers with writing electronic patient care reports (ePCRs) were revised as part of the agency's continuous quality improvement (QI) process. The agency's student leaders and medical directors collaborated to revise the documentation checklists when a needs analysis found opportunities for improvement in the performance and documentation of appropriately-focused physical exams.

Previously used checklists noted some criteria for commonly encountered chief complaints, but were outdated, inconsistent, and incomplete. The revised checklists incorporated more essential documentation elements for a wider range of chief complaints. Criteria for patient history, assessment, and intervention were organized separately in an easy-to-read format. GERMS has a QI committee that reviews each $\mathrm{ePCR}$ to measure compliance with current guidelines. Trends in patient documentation are shared at general membership meetings to highlight problems and areas for improvement. Prior to the adoption of these revised checklists, GERMS leadership oriented the membership during an annual Fall semester training workshop. The checklists were placed in the medical bags carried by members. 


\section{Objectives}

The study aimed to determine if and to what extent QI measures such as documentation checklists can improve inclusion of key documentation criteria on ePCRs in a collegiate-based EMS system.

\section{Methods}

In this retrospective chart review, the investigators analyzed GERMS ePCRs captured via emsCharts (Warrendale, PA). Charts written by providers from August 1, 2013, to July 31, 2015 were reviewed and

Table 1. Expanded documentation guidelines (for chief complaints analyzed).

\begin{tabular}{|c|c|c|c|c|}
\hline $\begin{array}{l}\text { Documentation } \\
\text { Element }\end{array}$ & Seizure or Syncope & Abdominal Pain & Chest Pain & $\begin{array}{l}\text { Trauma to } \\
\text { Head/Neck }\end{array}$ \\
\hline History & $\begin{array}{ll}\text { - } & \text { Loss of } \\
& \text { consciousness? } \\
\text { - } & \text { Last oral intake? } \\
\text { - } & \text { Alcohol/drug use? }\end{array}$ & $\begin{array}{ll}\text { - } & \text { SAMPLE }^{\dagger} \\
\text { - } & \text { OPQRST }^{\ddagger} \\
\text { - } & \text { History of trauma? } \\
\text { - Associated } \\
\text { Symptoms: } \\
\text { - Nausea, } \\
\text { vomiting, or } \\
\text { diarrhea? } \\
\text { - Weakness, } \\
\text { faintness? } \\
\text { - Respiratory } \\
\text { symptoms? } \\
\text { If applicable: } \\
\text { - Vaginal } \\
\text { bleeding? } \\
\text { - Pregnancy } \\
\text { status / last } \\
\text { menstrual } \\
\text { period? } \\
\text { Birth control? }\end{array}$ & $\begin{array}{ll}\text { - } & \text { SAMPLE }^{\dagger} \\
\text { - } & \text { OPQRST }^{\ddagger} \\
\text { - } & \text { Cardiac history } \\
\text { - } & \text { Location of pain } \\
\text { Associated } \\
\text { symptoms: } \\
\text { - Nausea or } \\
\\
\text { - } \quad \text { vomiting? } \\
\quad \text { Shortness of } \\
\text { breath? }\end{array}$ & $\begin{array}{ll}\text { - } & \text { Mechanism of } \\
\text { injury } \\
\text { - } & \text { OPQRST }^{\ddagger} \\
\text { - } & \text { Description of } \\
\text { surface } \\
\text { - } \quad \text { Loss of } \\
\text { consciousness? }\end{array}$ \\
\hline Assessment & $\begin{array}{ll}\text { - } & \text { Head/neck trauma } \\
\text { - } & \text { GCS } \\
\text { - } & \text { Gait } \\
\text { - } & \text { Pupillary response } \\
\text { - } & \text { Pronativity to light? } \\
\text { - } & \text { Motor exam } \\
\text { - } & \text { Sensory exam } \\
\text { - } & \text { Facial asymmetry? } \\
\text { - } & \text { Speech fluency } \\
\text { - } & \text { Blood glucose }\end{array}$ & $\begin{array}{ll}\text { - } & \text { Location of } \\
\text { tenderness } \\
\text { - } & \text { Abdominal } \\
\text { distention? } \\
\text { - } \\
\text { Abdominal } \\
\text { rigidity? }\end{array}$ & $\begin{array}{l}\text { - Pulse quality and } \\
\text { regularity } \\
\text { Skin color, } \\
\text { temperature, } \\
\text { moisture }\end{array}$ & $\begin{array}{ll}\text { - } & \text { Inspection of } \\
\text { head/neck } \\
\text { - } & \text { Palpation of head/ } \\
\text { neck } \\
\text { - } & \text { Neurological exam } \\
\text { - } & \text { Trending of } \\
\text { neurological status } \\
\text { - } \text { Distal } \\
\text { neurovascular } \\
\text { exam } \\
\text { - GCS }\end{array}$ \\
\hline Interventions* & 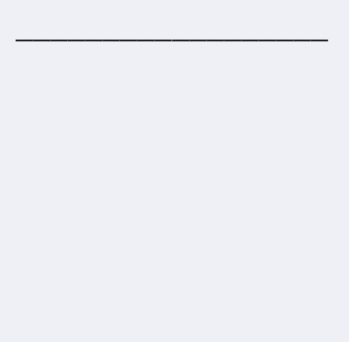 & - Oxygen & $\begin{array}{ll}\text { - } & \text { Oxygen } \\
\text { - } & \text { Aspirin } \\
\text { - } & \text { Nitroglycerin } \\
\text { - } & \text { Response to } \\
\text { - } & \text { medications } \\
& \text { Request for } \\
& \text { advanced life } \\
& \text { support }\end{array}$ & $\begin{array}{ll}\text { - } & \text { Immobilization } \\
\text { Request for } \\
\text { advanced life } \\
\text { support }\end{array}$ \\
\hline
\end{tabular}

*If intervention not applicable, documentation of reason(s) required.

†SAMPLE: Signs/Symptoms, Allergies, Medications, Past Medical History, Last Oral Intake, Events Prior

${ }^{\ddagger}$ OPQRST: Onset, Provocation/Palliation, Quality, Radiation, Severity, Time

${ }^{\varsigma}$ GCS: Glasgow Coma Scale 
included for analysis if the reported chief complaint was seizure/ syncope, abdominal pain, chest pain, or head/neck trauma. These chief complaints were specifically analyzed as they were identified as likely higher medico-legal risk categories by the GERMS QI committee. The stratification of risk was based on a consensus between GERMS' medical director, QI officer, QI committee, and similar QI initiatives in the metropolitan region. Two reviewers (A.A. and B.M.) then independently scored each patient report according to the revised documentation standard implemented on June 1, 2014. The score was calculated as a percentage of chief complaint-based criteria that were correctly documented. For study analysis, each chart's score was the average between the two reviewers, with a kappa statistic used to determine overall agreement.

The required documentation elements for the four chief complaints analyzed are listed in Table 1 . Documentation elements for each chief complaint are divided into history, assessment, and interventions. For each element, the reviewers were instructed to add 1 point if the providers documented the specific element in the chart narrative or 0 points if omitted. A score was then calculated as the percentage of total possible points. For this study, the reviewers examined only the free-text narrative portion of the chart.

Patient intervention criteria (in Table 1) were considered to be met if either performance of the intervention was specifically documented or an explanation for non-intervention was provided. For example, a patient with suspected head or neck trauma may not require immobilization if specifically noted in the chart to be inappropriate by the agency's immobilization patient care protocols or online medical direction.

To assess the impact of the QI initiative on EMS documentation quality, ePCRs were divided into two groups (pre-intervention and post-intervention) based on date of submission. ePCRs completed prior to June 1, 2014 were assigned to the pre-intervention group while subsequent reports were considered post-intervention. This date marked the introduction of the updated documentation checklists to the GERMS membership.

For each chief complaint and study group, the scores of the individual ePCRs were averaged to compare overall documentation pre- and post-intervention. Documentation frequency of individual criteria were subsequently calculated and compared between the two study groups. Two-sample t tests were used to compare the two study groups with significance defined as $P<0.05$. Inter-rater reliability was tested using the kappa statistic (Microsoft Excel, Redmond, WA). This study was reviewed and approved by the Georgetown University Institutional Review Board.

\section{Results}

A total of 373 charts met inclusion criteria and were analyzed in this study. A breakdown of the number of ePCRs per chief complaint analyzed in either the pre- or post-intervention phases is noted in Table 2.

Following the adoption of the updated documentation checklist, there were statistically significant increases in the overall inclusion of required documentation elements for all studied chief complaints: chest pain $(69.29 \%$ to $81.31 \%, P=0.006)$; abdominal pain (70.65\% to $80.82 \%, P<0.001)$; head trauma $(80.47 \%$ to $86.39 \%$, $P<0.001)$; seizure/syncope $(78.3 \%$ to $84.67 \%, P=0.012)$, as noted
Table 2. Number of electronic patient care reports (ePCRs) meeting inclusion criteria, specified by chief complaint.

\begin{tabular}{lcc} 
Chief Complaint & $\begin{array}{c}\text { Pre- } \\
\text { Intervention }\end{array}$ & $\begin{array}{c}\text { Post- } \\
\text { Intervention }\end{array}$ \\
\hline Seizure or Syncope & 42 & 56 \\
Abdominal Pain & 57 & 80 \\
Chest Pain & 12 & 14 \\
Head/Neck Trauma & 44 & 68 \\
\hline
\end{tabular}

in Figure 1.

Within each chief complaint, only some documentation elements showed statistically significant increases in frequency of documentation pre- and post-intervention (Table 3). The documentation of last oral intake for patients with abdominal pain slightly decreased after implementation of the revised checklists $(P=0.044)$.

The study investigators' inter-rater reliability was generally high, as noted by most kappa statistics being greater than 0.8 for these criteria (Table 3, Appendix S1). Kappa was less than 0.8 for a few elements, including: weakness/fatigue, location of pain, and radiation of pain (abdominal pain); nitroglycerin administration and call ahead to receiving facility (chest pain); pain on palpation and ALS dispatched (head trauma).

\section{Discussion}

Many barriers to effective EMS documentation exist. While the verbal handoff between EMS and emergency department providers is undoubtedly critical to patient care, it is often inaccurate, incomplete, or not heard. Information is lost amidst ongoing distractions, attempts to expedite care, and the need for provider-multitasking. Moreover, only about half of verbal information has shown to be retained by receiving ED staff even when structured handoff models are used. ${ }^{4}$ Prehospital written documentation ensures pertinent EMS information is communicated appropriately and available to the entire treatment team.

EMS providers receive little training on proper documentation. Producing a useful and relevant EMS chart is more complex than typing a narrative and checking boxes; learning how to collect and synthesize information, determine relevance, and recall necessary elements requires practice. Only 1.5 hours of the standard 110-hour EMT curriculum is specifically allocated to documentation. ${ }^{5}$ For collegiate-based EMS programs like GERMS, high turnover rates necessitate continuous training and reinforcement of documentation best-practices. The relatively low call volumes of CBEMS limits provider experience caring for and documenting certain chief complaints. Training time is also limited since members are typically full-time undergraduate students. Even on shift, members are often balancing academics and other extracurricular activities. Without adequate time and experience, explicit written instruction on documentation is invaluable.

This study supports documentation checklists as an effective 


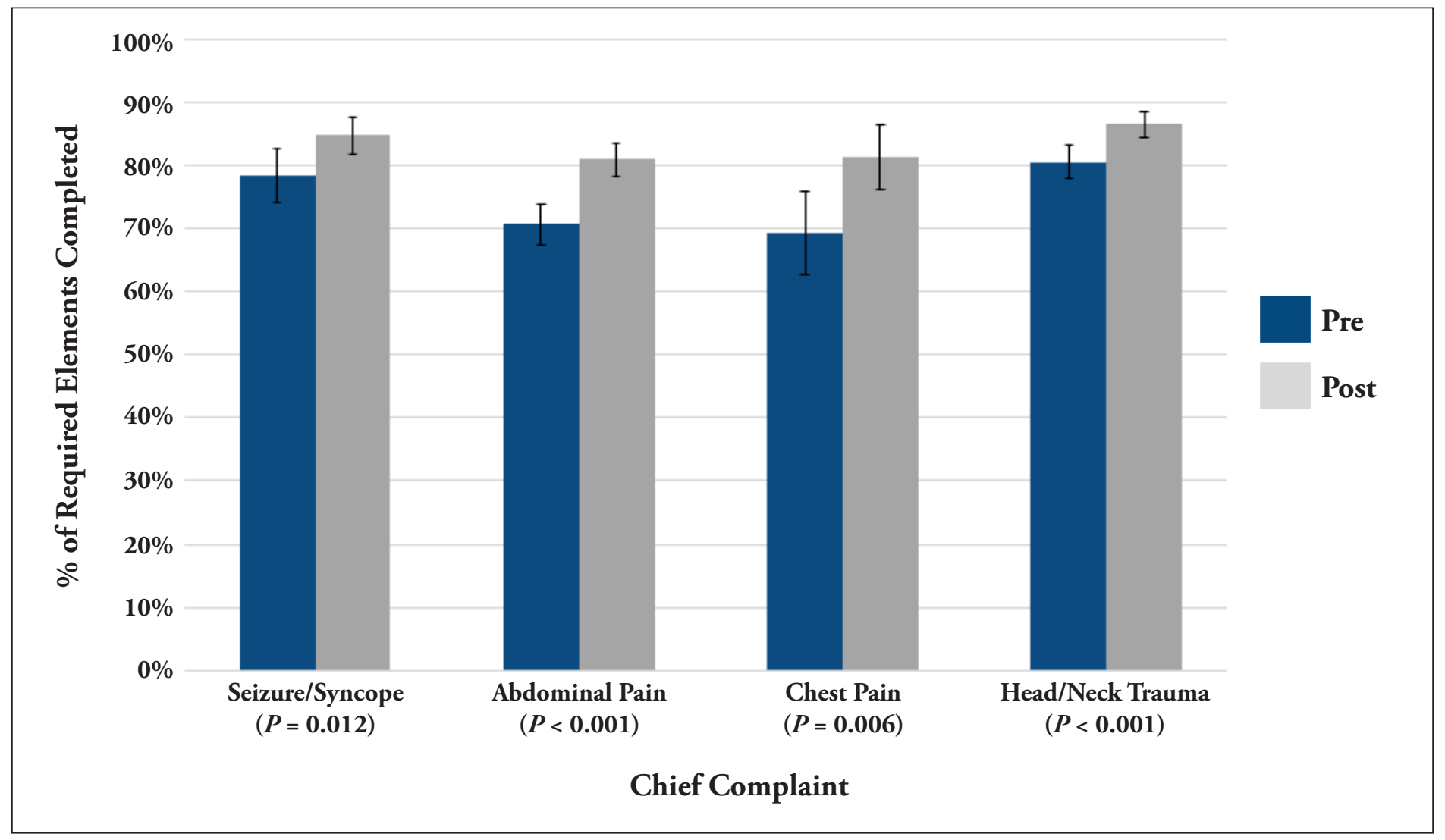

Figure 1. Compliance with required documentation elements. Data reported as the percentage of mandatory documentation elements from Table 1 that are incorporated in the ePCRs of all charts meeting inclusion criteria for the specific chief complaint. Error bars indicate $95 \%$ confidence intervals.

strategy to improve prehospital documentation in collegiate-based EMS. Within medicine, checklists are effective memory aids during stressful, time-sensitive situations such as cardiac resuscitation and rapid sequence intubation. ${ }^{6-8}$ Aviation checklists have long been used to safeguard against inevitable human error. ${ }^{9,10}$ Like aviation pilots, EMS providers are not immune to human error. Fatigue, stress, frequent distractions, and cognitive overload undoubtedly impact documentation quality. Delays in charting from long patient transfer times and multiple dispatches are frequent and lend to recall bias and documentation errors. A 2017 prospective, observational study revealed how documentation from memory can introduce significant error. Following completion of a simulated scenario, ten paramedic volunteers completed an ePCR before using a body-worn camera to check for accuracy and make changes. Serious documentation errors were made such as omission of patient suicidality or presence of weapons on scene. ${ }^{11}$

While documentation guidelines are often incorporated into the EMS organization's standard operating procedures (SOPs), checklists enhance guideline adherence. ${ }^{12,13}$ However, the introduction of a checklist alone to improve documentation is likely insufficient. Orientation of such checklists to the prehospital providers who will be using them is a vital aspect of ensuring compliance. ${ }^{14,15}$

In this study, inclusion of key documentation criteria significantly improved with the QI initiative and checklist revision. This suggests that the checklist revision and QI initiative increased provider compliance to current guidelines. Little inter-rater variability supports checklist-use as a reliable tool to assess documentation trends and provide performance-based feedback. The study's analysis of the free-text narrative portion of the chart, which may result in more subjectivity, may explain areas of poor inter-rater variability.

\section{Limitations}

This study is limited by its retrospective study design. The data is also derived from a single agency, potentially limiting generalizability.

Several uncontrolled variables may have influenced our results as well. Each year, GERMS leadership undergoes a complete turnover and new directors of training, continuing education, and operations are elected. Crew officers, who oversee patient care and documentation, also frequently change. In October 2014, a new medical director was appointed to serve GERMS and supervised the QI efforts - developed jointly with the GERMS leadership and both the incoming and outgoing medical directors - which were ultimately implemented in June 2014. After implementation, more focused attention was given to accurate, complete documentation. The scores of individual members were tracked providing an increased incentive to adhere to the documentation checklist. Areas where consistent deficits were identified were addressed with group-wide training.

Lastly, although our study measured the quantitative improvement of documentation of checklist items, additional qualitative measures of PCR quality (e.g., clarity of narrative) were not evaluated in this study. 
Table 3. Comparison of frequency of documentation of required elements (Table 1) prior to and after the implementation of the expanded documentation guidelines. Only elements with a pre- and post-intervention difference meeting statistical significance are included (data for all elements included in Appendix S1). The inter-rater reliability for each element is noted by the kappa statistic.

\begin{tabular}{|c|c|c|c|c|}
\hline Documentation Element & Pre-Intervention & Post-Intervention & $P$-Value & Kappa Statistic \\
\hline \multicolumn{5}{|l|}{ Syncope or Seizure } \\
\hline Last Oral Intake & $79.3 \%$ & $91.7 \%$ & 0.010 & 0.907 \\
\hline Alcohol/Drug Use & $64.4 \%$ & $84.2 \%$ & 0.001 & 0.979 \\
\hline Glascow Coma Scale Score & $90.8 \%$ & $98.3 \%$ & 0.013 & 0.979 \\
\hline Speech Fluency & $83.7 \%$ & $94.1 \%$ & 0.015 & 0.928 \\
\hline \multicolumn{5}{|l|}{ Abdominal Pain } \\
\hline Pregnancy/Last Menstrual Period & $87.7 \%$ & $96.8 \%$ & 0.012 & 0.942 \\
\hline Last Oral Intake & $95.7 \%$ & $89.02 \%$ & 0.044 & 0.912 \\
\hline Nausea/Vomiting/Diarrhea & $94.8 \%$ & $99.4 \%$ & 0.012 & 0.963 \\
\hline Weakness/Fatigue & $25.2 \%$ & $77.5 \%$ & $<0.001$ & 0.753 \\
\hline Vaginal Bleeding & $30.1 \%$ & $56.6 \%$ & $<0.001$ & 0.862 \\
\hline Radiation of Pain & $44.9 \%$ & $63.2 \%$ & 0.003 & 0.578 \\
\hline Rigidity of Abdomen & $61.3 \%$ & $73.1 \%$ & 0.037 & 0.913 \\
\hline \multicolumn{5}{|l|}{ Chest Pain } \\
\hline Nausea/Vomiting & $37.5 \%$ & $85.7 \%$ & $<0.001$ & 0.882 \\
\hline Response to Medications & $53.3 \%$ & $93.3 \%$ & 0.012 & 0.805 \\
\hline \multicolumn{5}{|l|}{ Head/Neck Trauma } \\
\hline Initial Neurological Exam & $81.8 \%$ & $91.9 \%$ & 0.023 & 0.901 \\
\hline Trending of Neurological Status & $40.9 \%$ & $81.6 \%$ & $<0.001$ & 0.830 \\
\hline Glascow Coma Scale Score & $95.5 \%$ & $100 \%$ & 0.012 & 1.000 \\
\hline
\end{tabular}

\section{Conclusions}

In this retrospective chart review, standardization and expansion of an existing set of documentation criteria was followed by an increase in both adherence to overall documentation standards and frequency of documentation of individual elements. Collegiate-based EMS agencies may consider checklists as a potential tool to improve the thoroughness of documentation.

\section{Acknowledgments}

The authors acknowledge the dedicated members of Georgetown Emergency Response Medical Service.

\section{References}

1. Hagiwara MA, Magnusson C, Herlitz J, et al. Adverse events in prehospital emergency care: a trigger tool study. BMC Emerg Med. 2019;19(1):14. https:// doi.org/10.1186/s12873-019-0228-3

2. Laudermilch DJ, Schiff MA, Nathens AB, Rosengart MR. Lack of emergency 
medical services documentation is associated with poor patient outcomes: a validation of audit filters for prehospital trauma care. J Am Coll Surg. 2009;210(2):220-227. https://doi.org/10.1016/j.jamcollsurg.2009.10.008

3. Joyce SM, Dutkowski KL, Hynes T. Efficacy of an EMS quality improvement program in improving documentation and performance. Prehosp Emerg Care. 1997;1(3):140-4. https://doi.org/10.1080/10903129708958807

4. Talbot R. Bleetman A. Retention of information by emergency department staff at ambulance handover: do standardised approaches work? Emerg Med J. 2007;24(8):539-542. https://doi.org/10.1136/emj.2006.045906

5. U.S. Department of Transportation National Highway Traffic Safety Administration. EMT-Basic: National Standard Curriculum. https://www. ems.gov/pdf/education/Emergency-Medical-Technician/EMT_Basic_1996. pdf. Accessed 25 May 2019.

6. Bloomer R, Burns BJ, Ware S. Improving documentation in prehospital rapid sequence intubation: investigating the use of a dedicated airway registry form. Emerg Med J. 2013;30(4):324-6. https://doi.org/10.1136/ emermed-2011-200715

7. Fee-Mulhearn AL, DePriest J, Teleron A. A novel ACLS team leader checklist implemented to improve resuscitation efforts. Resuscitation. 2013;84(9):e115. https://doi.org/10.1016/j.resuscitation.2013.03.002

8. Mommers L, Keogh S. SPEEDBOMB: a simple and rapid checklist for Prehospital Rapid Sequence Induction. Emerg Med Australas. 2015;27(2):1658. https://doi.org/10.1111/1742-6723.12363

9. Helmreich RL. On error management: lessons from aviation. BMJ. 2000;320(7237):781-5. https://doi.org/10.1136/bmj.320.7237.781

10. McCune K. Reducing error, improving safety. Doctors could certainly take lessons from aviation. BMJ. 2000;321(7259):506.

11. Ho JD, Dawes DM, McKay EM., et al. Effect of body-worn cameras on EMS documentation accuracy: a pilot study. Prehosp Emerg Care. 2017;21(2):263271. https://doi.org/10.1080/10903127.2016.1218984

12. Chen C, Kan T, Li S, Qiu C, Gui L. Use and implementation of standard operating procedures and checklists in prehospital emergency medicine: a literature review. Am J Emerg Med. 2016;34(12):2432-2439. https://doi. org/10.1016/j.ajem.2016.09.057

13. Ko HC, Turner TJ, Finnigan MA. Systematic review of safety checklists for use by medical care teams in acute hospital settings--limited evidence of effectiveness. BMC Health Serv Res. 2011;11:211. https://doi. org/10.1186/1472-6963-11-211

14. Kerner T, Schmidbauer W, Tietz M, Marung H, Genzwuerker HV. Use of checklists improves the quality and safety of prehospital emergency care. Eur J Emerg Med. 2017;24(2):114-119. https://doi.org/10.1097/ MEJ.0000000000000315

15. Ross DW, Schullek JR, Homan MB. EMS triage and transport of intoxicated individuals to a detoxification facility instead of an emergency department. Ann Emerg Med. 2013;61(2):175-84. https://doi.org/10.1016/j. annemergmed.2012.09.004

\section{Supplementary Materials}

Appendix S1: Complete version of Table 3 - Comparison of frequency of documentation of required elements prior to and after the implementation of the expanded documentation guidelines (available on-line).

Author Affiliations: From Georgetown University / MedStar Washington Hospital Center Emergency Medicine Residency Program, Washington, DC, USA (A.S.A.); Georgetown Emergency Response Medical Service, Georgetown University, Washington, DC, USA (A.S.A., B.V.M., A.D.R., K.B.H., J.T.V., J.V.N.); Georgetown University School of Medicine, Washington, DC, USA (A.S.A., B.V.M., A.D.R., K.B.H., J.V.N.); Temple University General Surgery Residency Program, Philadelphia, PA, USA (B.V.M.); Temple University Emergency Medicine Residency Program, Philadelphia, PA, USA (A.D.R.); St. Lawrence Health System, Canton-Potsdam Hospital, Potsdam, NY, USA (J.T.V.); Department of Emergency Medicine, MedStar Georgetown University Hospital, Washington, DC, USA (K.B.H., J.V.N).

Address for Correspondence: Jose V. Nable, MD, MS, NRP. 3800 Reservoir Rd NW, Department of Emergency Medicine, G-CCC., Washington, DC 20007. E-mail: Jose.Nable@georgetown.edu

Conflicts of Interest/Funding Sources: By the JCEMS Submission Declaration Form, all authors are required to disclose all potential conflicts of interest and funding sources. All authors declared that they have no conflicts of interest. All authors declared that they did not receive funding to conduct the research and/or writing associated with this work.

Authorship Criteria: By the JCEMS Submission Declaration Form, all authors are required to attest to meeting the four ICMJE.org authorship criteria: (1) Substantial contributions to the conception or design of the work; or the acquisition, analysis, or interpretation of data for the work; AND (2) Drafting the work or revising it critically for important intellectual content; AND (3) Final approval of the version to be published; AND (4) Agreement to be accountable for all aspects of the work in ensuring that questions related to the accuracy or integrity of any part of the work are appropriately investigated and resolved.

Prior Presentation: Preliminary data from this study were presented in abstract form at Georgetown University School of Medicine's Student Research Day on April 23, 2018 in Washington, DC, USA.

Submission History: Received May 28, 2019; accepted for publication February 2, 2020.

Published Online: February 28, 2020

Published in Print: February 28, 2020 (Volume 3: Issue 1)

Reviewer Information: In accordance with JCEMS editorial policy, Original Research manuscripts undergo double-blind peer-review by at least two independent reviewers. JCEMS thanks the anonymous reviewers who contributed to the review of this work.

Copyright: (C) 2020 Alatis, Monahan, Raymond, Hudson, Vieth \& Nable. This is an open access article distributed under the terms of the Creative Commons Attribution 4.0 International (CC BY 4.0) License, which permits unrestricted use, distribution, and reproduction in any medium, provided the original author and source are credited. The full license is available at: https://creativecommons.org/licenses/by/4.0/

Electronic Link: https://doi.org/10.30542/JCEMS.2020.03.01.05 


\title{
Prehospital Antiemetic Therapy in Campus-Based EMS Services:
}

\author{
A Cross-Sectional analysis of Statewide EMS Protocols
}

\author{
Carlin C. Chuck, BS, NREMT; Roshini Kalagara, NREMT; Isabelle Moseley, NREMT; Thomas J. Martin, BA, NRP
}

ABSTRACT

Background: Nausea is a common chief complaint in the prehospital setting, and collegiate-based emergency medical services (CBEMS) providers frequently encounter nausea secondary to alcohol intoxication. Objectives: We hypothesized that high variability would be present in statewide protocols at all prehospital provider levels, limiting the use of these therapies in particular for CBEMS organizations operating at the BLS level. Methods: A cross-sectional analysis of publicly available statewide emergency medical services (EMS) protocols was completed in October 2018 and updated in August 2019 examining presence of antiemetic therapies at each provider level. The licensure levels of CBEMS organizations affiliated with the National Collegiate Emergency Medical Services Foundation (NCEMSF) within each state were obtained from the NCEMSF Organization Database. Results: We identified 33 publicly available model or mandatory statewide EMS protocols which contained an antiemetic protocol/therapy. Of these, five (15.2\%) included antiemetic therapies at the basic life support (BLS) level. In addition, 256

KEYWORDS: collegiate-based emergency medical services; emergency medical technician; ondansetron; prehospital; Zofran

Corresponding Author and Author Affiliations: Listed at the end of this article.
$\mathrm{I}$ $\mathrm{n}$ the United States, nausea is the chief complaint in up to five million ED visits annually. ${ }^{1}$ In the prehospital setting, nausea with and without vomiting occurs in up to $10 \%$ of patients. ${ }^{2}$ Nausea may result from a gastrointestinal syndrome, but may also occur secondary to trauma, cardiogenic causes, or - of particular relevance in the college or university setting - the use of alcohol and other drugs. ${ }^{3,4}$ Nausea and vomiting are distressing to patients and present the risk of aspiration. ${ }^{2}$

Ondansetron (marketed under the brand name Zofran) is routinely used as an antiemetic treatment to relieve nausea and prevent vomiting. Several formulations are available, including oral (PO), oral dissolving tablets (ODT), intravenous (IV), and intramuscular (IM). Studies suggest that ondansetron can be safely and effectively administered by prehospital providers at the advanced life support (ALS) level via IV, IM, and oral routes. ${ }^{5-8}$ However, there is a lack of literature on the administration of ondansetron by providers at the basic life support (BLS) level.

Nausea and vomiting may also be managed with pharmaceuticals such as metoclopramide as well as noninvasive treatments in-

Carlin C. Chuck, BS, NREMT is a first-year medical student at Warren Alpert Medical School at Brown University who has been working as an EMT since his undergraduate years. Roshini Kalagara, NREMT is an undergraduate senior at Brown University. Isabelle Moseley, NREMT is an undergraduate senior at Brown University. Thomas J. Martin, BA, NRP is a medical student at Warren Alpert Medical School at Brown University and a paramedic. cluding isopropyl alcohol aromatherapy and P6 acupressure. Isopropyl alcohol aromatherapy is a nausea treatment in which patients nasally inhale isopropyl alcohol, typically through pads soaked in isopropyl alcohol. Some studies have demonstrated efficacy of isopropyl alcohol aromatherapy for nausea treatment in the $\mathrm{ED}^{9,10}$ but other studies of postoperative nausea suggest that isopropyl alcohol aromatherapy with ondansetron does not provide benefit over ondansetron alone. ${ }^{11}$ An ongoing clinical trial is investigating the administration of isopropyl alcohol aromatherapy in the prehospital setting by providers at the ALS level. ${ }^{12}$

Another noninvasive antiemetic therapy is $\mathrm{P} 6$ acupressure, which draws its roots from traditional Chinese acupuncture. The treatment involves the application of pressure to the P6 acupressure point, located approximately three finger-widths from the wrist in the middle of the forearm. However, the efficacy of P6 acupressure in the medical setting is an area of debate. One randomized control trial (RCT) suggested short-term nausea relief in post-operative thyroidectomy, ${ }^{13}$ although two other RCTs regarding post-operative nausea in laparoscopic cholecystectomy and craniotomy both suggested no significant difference between $\mathrm{P} 6$ acupressure and a control. ${ }^{9,10}$ However, no studies have tested the effectiveness of P6 acupressure in the prehospital setting.

In the United States, the treatment options available to prehospital providers are dictated by written protocols as well as on-line or off-line orders from medical direction. States may create mandatory 
protocols that must be followed by all EMS providers in the state or model protocols which regional or local authorities may choose to adopt. ${ }^{14}$ The development of statewide protocols is often informed by the National EMS Model Guidelines, produced by the National Association of EMS Officials. ${ }^{15}$ Although many states do not rely on mandatory or model statewide protocols, ${ }^{14}$ statewide protocols provide an indicator of available therapeutic options and current practices.

\section{Objectives}

We sought to characterize the variability across statewide protocols of the prehospital management of nausea at the BLS level. As a secondary aim, we sought to determine the number of BLS-level CBEMS organizations in states with BLS protocols that include antiemetic therapy.

\section{Methods}

A cross-sectional analysis of publicly available statewide EMS protocols was completed in October $2018^{16}$ and updated in August 2019. State Department of Health websites as well as Google searches were utilized to identify publicly available statewide EMS protocols (Alphabet Inc, Menlo Park, CA, USA). Search terms included each state name (including Washington, DC) followed by "EMS protocols"; for example, the first search term was "Alabama EMS protocols." In addition, a list of protocols in a previously published analysis of statewide protocols by Kupas et al. (2015) was reviewed. ${ }^{14}$ Both model and mandatory state protocols, as defined by Kupas et al. (2015), were included for analysis. We also reviewed the National Model EMS Guidelines. ${ }^{15}$ For data abstraction, state licensure levels were defined as:

- Basic Life Support (BLS): Emergency Medical Technician (EMT)

- Intermediate Life Support (ILS): Advanced Emergency Medical Technician (AEMT)

- $\quad$ Advanced Life Support (ALS): Paramedic

All states with protocols for nausea management or antiemetic therapies (including in protocols for pain comfort/management) were included for analysis, provided the protocols had been published within the last 10 years. The following data was abstracted from statewide protocols:

- Presence of statewide protocol for nausea/vomiting management.

- Antiemetic therapies at provider level (BLS, ILS, and ALS), with PO and ODT ondansetron defined as an outcome of interest. Other outcomes of interest included alternative antiemetic therapies such as isopropyl alcohol aromatherapy or $\mathrm{P} 6$ acupressure.

- Presence of medical alternatives to ondansetron (metoclopramide, promethazine, etc.).

The publicly available National Collegiate EMS Foundation (NCEMSF) Organization Database was reviewed in October 2018 to identify all CBEMS organizations registered with NCEMSF. ${ }^{17}$ For all states with publicly available statewide nausea or antiemetic therapy protocols, we recorded the number of agencies and each agency's licensure level as categorized in the NCEMSF Organization
Database: First Responder, Basic Life Support, Intermediate Life Support, or Advanced Life Support. Two trained reviewers (C.C., I.M.) independently collected data from statewide protocols using standardized abstraction forms; interrater reliability was assessed using Cohen's $\kappa$ and any discrepancies were resolved by the senior author (T.M.). Descriptive statistics were generated using R v3.3.2 (The R Foundation for Statistical Computing, 2018).

\section{Results}

We identified 34 states (including Washington, DC) with publicly available model or mandatory statewide protocols published within the past 10 years. Of the 34 states, 33 include protocols for prehospital nausea management or antiemetic therapies (Figure 1). Compared to previous literature which excluded 12 states from analysis, ${ }^{14}$ our study excluded 17 states from analysis and included the District of Columbia. With respect to the five states included by Kupas et al. (2015) that we did not analyze, ${ }^{14}$ Illinois and Alaska no longer have their statewide protocols publicly available; Nevada no longer has statewide protocols; California delegates protocol development to local authorities; and Washington state has not updated their online protocols since 2005 . Montana has a publicly available statewide protocol, but delegates development of nausea protocols to local EMS authorities. Of note, Minnesota only provided BLS protocols and ALS protocols for pediatrics, while South Dakota only provided BLS protocols. We abstracted data on antiemetic therapies from protocols for nausea management, patient comfort, or pain management with $\kappa=1$.

Of the 33 states with statewide protocols for prehospital nausea management, $5(15.2 \%)$ contain protocols at the BLS level. Two states permit administration of ODT ondansetron (West Virginia, Delaware), one permits the use of isopropyl alcohol aromatherapy (New Hampshire), and two permit acupressure at the P6 point through manual techniques or use of a commercial device (Maryland, New Mexico) (Figure 2). Arkansas includes ODT ondansetron in their protocol, but the protocol did not specify whether this is limited to ALS providers. We did not identify any protocols permitting use of intramuscular antiemetics at the BLS level.

Considering BLS, ILS, and ALS provider levels, 26 states (78.8\%) have protocols that include ODT ondansetron, with 23 (70.0\%) of these protocols restricting ODT ondansetron administration to ILS and higher-level providers. Ten states (30.3\%) restrict ODT ondansetron administration exclusively to ALS providers (Figure 2).

The National Model EMS Guidelines also has a nausea protocol. ${ }^{15}$ This protocol includes both IV and ODT ondansetron but does not specify protocol scope-of-practice between various provider levels. This model protocol also includes the antiemetic alternatives of metoclopramide, prochlorperazine, diphenhydramine, and isopropyl alcohol, but does not include P6 acupressure.

In total, 256 CBEMS organizations were identified in the NCEMSF Organization Database, of which 162 (63\%) operate at the BLS level (Appendix S1). Eight of the identified BLS organizations were found to operate within states that contain a BLS therapy for nausea. Two of these CBEMS organizations were in states that have statewide BLS protocols for ODT ondansetron (1 in West Virginia; 1 in Delaware); 4 were in a state with a BLS protocol for isopropyl alcohol aromatherapy (New Hampshire); and two were in 


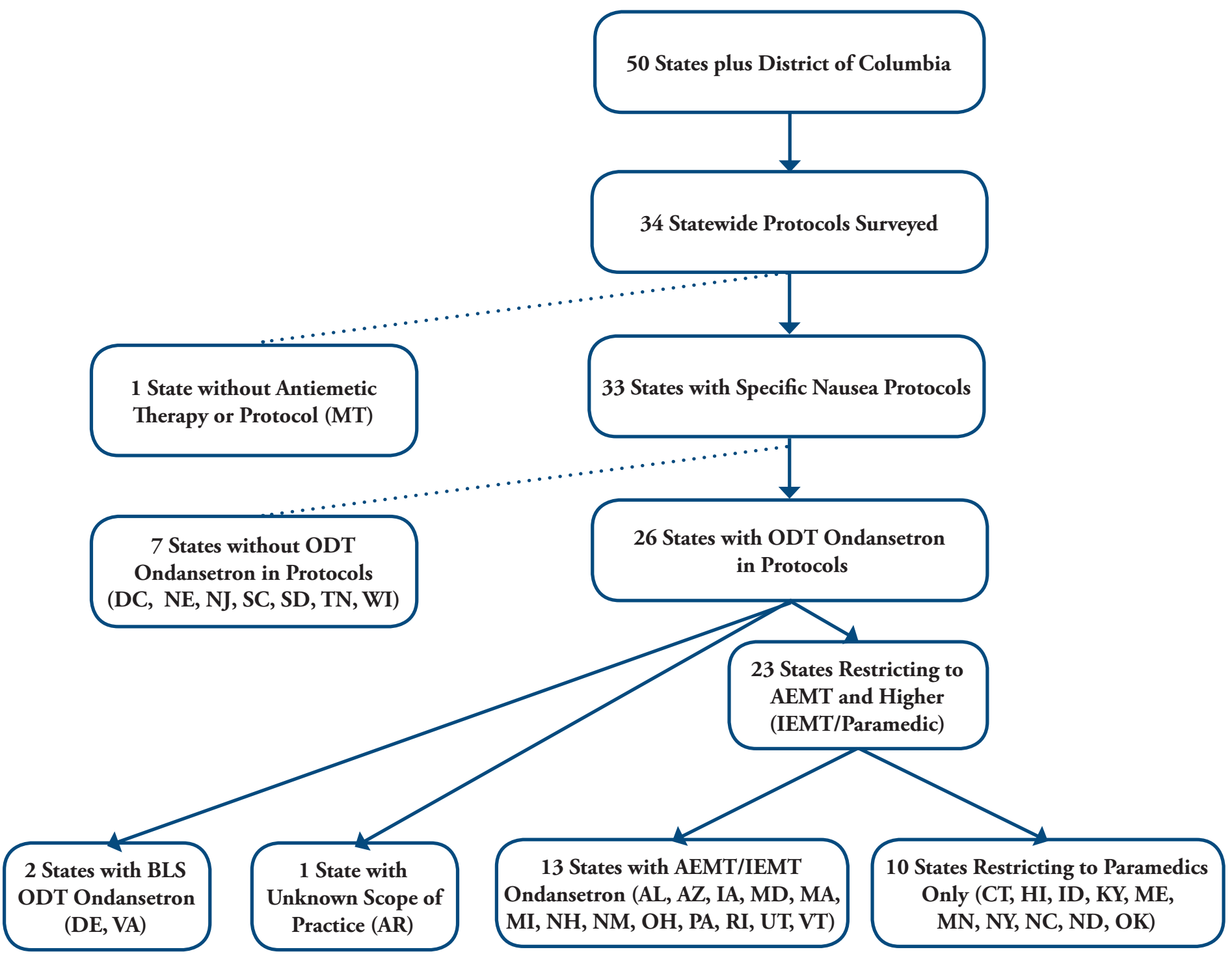

Figure 1. Flowchart of oral dissolving tablet (ODT) ondansetron protocols included by state and EMS provider level.

a state with a BLS protocol for acupressure (Maryland).

\section{Discussion}

Our data demonstrate that the vast majority of NCEMSF-affiliated CBEMS agencies at the BLS level are unable to provide antiemetic therapy, as most states with publicly available statewide protocols do not offer a BLS therapy for nausea. Only West Virginia and Delaware currently allow BLS providers to provide ODT ondansetron. While ODT ondansetron is readily available in the formularies of most states identified within the study, most states restrict ODT ondansetron to ILS or ALS providers.

Studies suggest that ODT ondansetron is as safe and effective as IV ondansetron in the hospital postoperative setting ${ }^{18}$ as well as superior to saline in the prehospital setting. ${ }^{8}$ While evidence supports the effectiveness of ondansetron in the prehospital setting with ALS providers ${ }^{7,19}$ further research is needed on its usage among BLS providers. Of note, one prehospital paramedic-restricted study showed
IV administration of ondansetron to have a stronger effect on nausea than ODT administration. ${ }^{5}$

One possible rationale for the restriction of ondansetron administration by BLS providers is the potential for adverse reactions. Ondansetron administration may lead to cardiac arrhythmias through QT prolongation, ${ }^{10}$ and thus should be used with caution among patients with congenital or acquired Long QT syndrome. BLS providers are unable to measure QT intervals with an EKG, which could lead to inappropriate administration of ondansetron for patients with comorbid factors.

CBEMS agencies are also impacted by the lack of inclusion of alternative antiemetic therapies in statewide EMS protocols. However, our study demonstrates that the rate of adoption of alternative antiemetic therapies at the BLS, ILS, or ALS provider levels remains exceedingly low in statewide protocols. In addition, disagreements over appropriate dosage of isopropyl alcohol aromatherapy have yet to be resolved. For example, one study involved three inhalations of isopropyl alcohol over four minutes, ${ }^{20}$ while New Hampshire EMS protocols suggest the same three doses over 15 minutes. $^{21}$ The clin- 


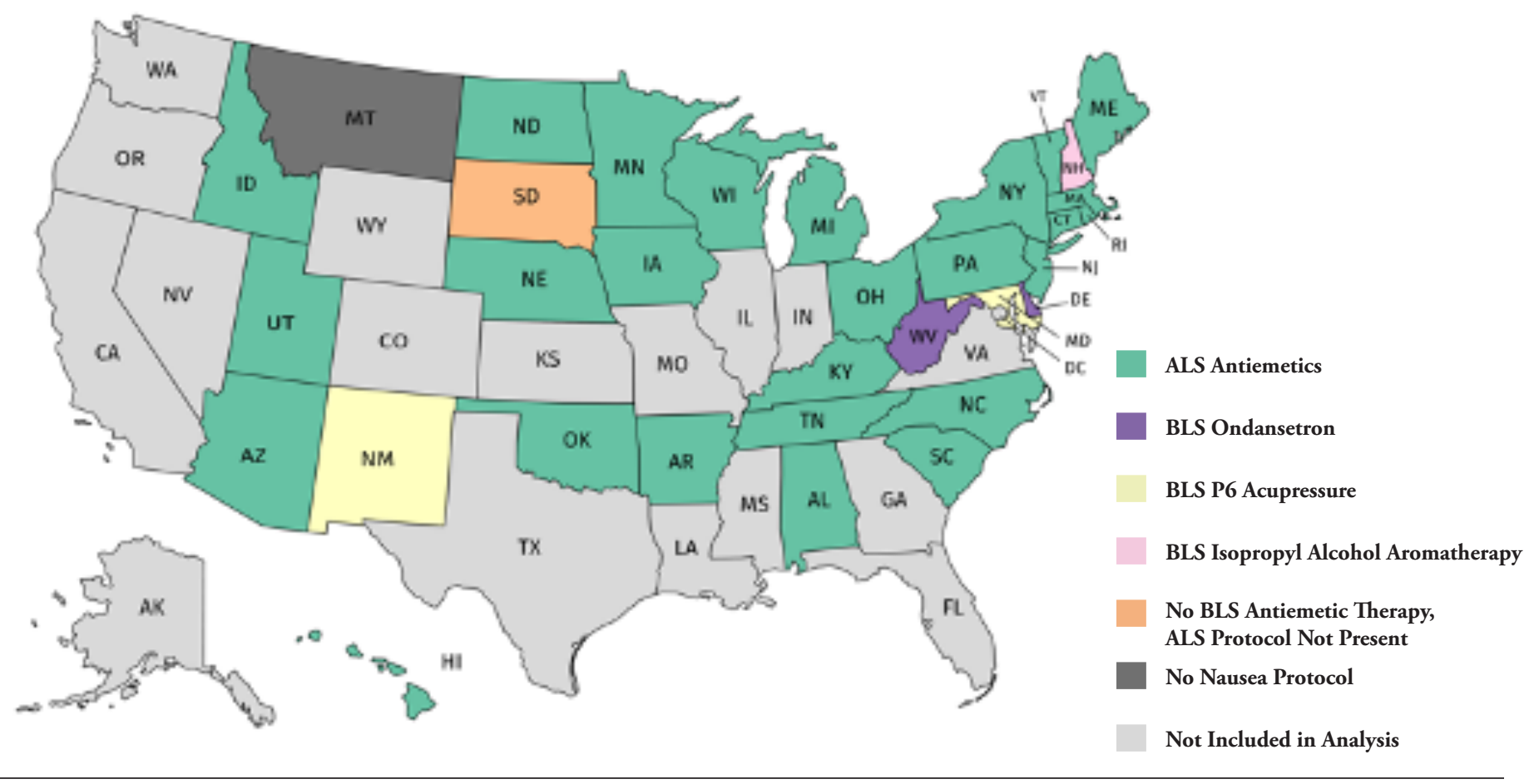

Figure 2. A geographical representation of antiemetic therapy EMS protocols across the United States.

ical effectiveness of P6 acupressure lacks a strong evidence base, as noted by conflicting results of studies on its use in the hospital setting ${ }^{12-14,18,19}$ and a lack of studies on its use in the prehospital setting. Further research should aim to understand appropriate dosages, pharmacodynamics, and efficacy of various antiemetic alternatives to ondansetron such as isopropyl alcohol aromatherapy and P6 acupressure. Further research should also explore the effectiveness, safety, and feasibility of their administration by BLS providers in the prehospital setting.

\section{Limitations}

Our inclusion criteria limited analysis to states with publicly available statewide protocols. This differed from previous literature regarding protocol availability and is a limitation of this study. ${ }^{14}$ Changes in protocol guidelines at both state and local levels or changes in the public availability of these protocols affected our ability to survey the same statewide protocols as previous literature. ${ }^{14}$

In addition, this study does not survey the "protocol of practice" or lex terrae. Many states rely on regional, county, or system-based EMS protocols in the absence of or in conjunction with statewide guidelines. This means that it is possible that implementation and adherence to statewide protocols may vary drastically between individual EMS systems. This effect is likely to be especially pronounced in states with model statewide protocols, where local EMS protocols may vary from the published model. Since we did not survey NCEMSF-affiliated agencies to assess their adherence to statewide protocols, it is possible that prehospital antiemetic therapies are used more or less frequently than recommended in statewide protocols. Therefore, this study was not able to directly measure the prevalence of prehospital nausea management.

\section{Conclusions}

This cross-sectional analysis of statewide EMS protocols demonstrates that the majority of CBEMS agencies operate in geographic areas where statewide protocols do not allow antiemetic therapies at the BLS level. However, a few select states have implemented protocols using ODT ondansetron, isopropyl alcohol aromatherapy, or P6 acupressure to provide antiemetic therapies at the BLS level prehospitally. Further research should assess the effectiveness and safety of ODT ondansetron and alternative antiemetic therapies as BLS interventions in collegiate EMS settings. States should consider the pros and cons of expanding their BLS nausea protocols during future updates.

\section{References}

1. Myer PA, Mannalithara A, Singh G, Singh G, Pasricha PJ, Ladabaum U. Clinical and Economic Burden of Emergency Department Visits Due to Gastrointestinal Diseases in the United States. Am J Gastroenterol. 2013;108(9):1496-1507. https://doi.org/10.1038/ajg.2013.199

2. Easton R, Bendinelli C, Sisak K, Enninghorst N, Balogh Z. Prehospital nausea and vomiting after trauma: Prevalence, risk factors, and development of a predictive scoring system. J Trauma Acute Care Surg. 2012;72(5):1249-1253; discussion 1253-1254. https://doi.org/10.1097/TA.0b013e318249668e

3. Parashette KR, Croffie J. Vomiting. Pediatr Rev. 2013;34(7):307-321. https:// doi.org/10.1542/pir.34-7-307

4. Metz A, Hebbard G. Nausea and vomiting in adults--a diagnostic approach. Aust Fam Physician. 2007;36(9):688-692.

5. Salvucci AA, Squire B, Burdick M, Luoto M, Brazzel D, Vaezazizi R Ondansetron is safe and effective for prehospital treatment of nausea and vomiting by paramedics. Prehosp Emerg Care. 2011;15(1):34-38. https://doi.or g/10.3109/10903127.2010.519822 
6. Abouleish EI, Rashid S, Haque S, Giezentanner A, Joynton P, Chuang AZ. Ondansetron versus placebo for the control of nausea and vomiting during Caesarean section under spinal anaesthesia. Anaesthesia. 1999;54(5):479-482. https://doi.org/10.1046/j.1365-2044.1999.00798.x

7. Benner JP, Ferguson JD, Judkins AE, O'Connor RE, Brady WJ. Ondansetron as an effective antiemetic in the rural, out-of-hospital setting. Am J Emerg Med. 2011;29(7):818-821. https://doi.org/10.1016/j.ajem.2011.03.022

8. Fullerton L, Weiss SJ, Froman P, Oglesbee S, Cheney P. Ondansetron oral dissolving tablets are superior to normal saline alone for prehospital nausea. Prehosp Emerg Care. 2012;16(4):463-468. https://doi.org/10.3109/10903127 .2012 .695430

9. Yilmaz Sahin S, Iyigun E, Can MF. Effect of acupressure application to the P6 acupoint before laparoscopic cholecystectomy on postoperative nausea-vomiting: A randomized controlled clinical study. Int J Nurs Stud. 2018;87:40-48. https://doi.org/10.1016/j.ijnurstu.2018.07.011

10. Nilsson I, Karlsson A, Lindgren L, Bergenheim T, Koskinen L-O, Nilsson U. The efficacy of $\mathrm{P} 6$ acupressure with sea-band in reducing postoperative nausea and vomiting in patients undergoing craniotomy: a randomized, doubleblinded, placebo-controlled study. J Neurosurg Anesthesiol. 2015;27(1):42-50. https://doi.org/10.1097/ANA.0000000000000089

11. Radford KD, Fuller TN, Bushey B, Daniel C, Pellegrini JE. Prophylactic isopropyl alcohol inhalation and intravenous ondansetron versus ondansetron alone in the prevention of postoperative nausea and vomiting in high-risk patients. AANA J. 2011;79(4 Suppl):S69-74.

12. EMS Use of Isopropyl Alcohol Aromatherapy Versus Ondansetron - Full Text View - ClinicalTrials.gov. https://clinicaltrials.gov/ct2/show/NCT02618343. Published December 1, 2015. Updated April 2, 2019. Accessed February 5, 2020.

13. Kwon J-H, Shin Y, Juon H-S. Effects of Nei-Guan (P6) Acupressure Wristband: On Nausea, Vomiting, and Retching in Women After Thyroidectomy. Cancer Nurs. 2016;39(1):61-66. https://doi.org/10.1097/ NCC. 0000000000000243

14. Kupas DF, Schenk E, Sholl JM, Kamin R. Characteristics of statewide protocols for emergency medical services in the United States. Prehosp Emerg Care. 2015;19(2):292-301. https://doi.org/10.3109/10903127.2014.964891

15. Medical Directors Council, National Association of State EMS Officials National Model EMS Clinical Guidelines: Version 2.2. https://nasemso.org/ projects/model-ems-clinical-guidelines/. Published January 2019. Accessed January 28, 2020.

Chuck CC, Martin NTJ, Moseley IH, Ranney ML, Asselin. No IV, No Problem: A Cross Sectional Analysis of Antiemetic Therapies in Statewide EMS Protocols. J Coll Emerg Med Serv. 2019;2(S1):S4. https://doi. org/10.30542/JCEMS.2019.02.S1.04

16. National Collegiate Emergency Medical Services Foundation EMS Organization Database. https://www.ncemsf.org/resources/ems-organizationdatabase/groups-listed-by-region. Accessed February 5, 2020.

17. Fox-Geiman MP, Fisher SG, Kiley K, Fletcher-Gonzalez D, Porter N, Stiff P. Double-blind comparative trial of oral ondansetron versus oral granisetron versus IV ondansetron in the prevention of nausea and vomiting associated with highly emetogenic preparative regimens prior to stem cell transplantation. Biol Blood Marrow Transplant. 2001;7(11):596-603. https:// doi.org/10.1053/bbmt.2001.v7.pm11760147
18. Moffett PM, Cartwright L, Grossart EA, O'Keefe D, Kang CS. Intravenous Ondansetron and the QT Interval in Adult Emergency Department Patients: An Observational Study. Acad Emerg Med. 2016;23(1):102-105. https://doi. org/10.1111/acem.12836

19. Beadle KL, Helbling AR, Love SL, April MD, Hunter CJ. Isopropyl Alcohol Nasal Inhalation for Nausea in the Emergency Department: A Randomized Controlled Trial. Ann Emerg Med. 2016;68(1):1-9.e1. https://doi. org/10.1016/j.annemergmed.2015.09.031

20. Division of Fire Standards and Training \& Emergency Medical Services, New Hampshire Department of Safety. Patient Care Protocols, Version 7.1. https://www.nh.gov/safety/divisions/fstems/ems/advlifesup/patientcare.html. Published April 2018. Accessed February 7, 2020.

\section{Supplementary Materials}

Appendix S1: Table - Number of NCEMSF agencies in states included in analysis, by state and responder level (available on-line).

Author Affiliations: From The Warren Alpert Medical School of Brown University, Providence, RI, USA (C.C.C, T.J.M.); Brown University, Providence, RI, USA (I.M., R.K.).

Address for Correspondence: Carlin C. Chuck, BS, NREMT.

E-mail: carlin_chuck@brown.edu

Conflicts of Interest/Funding Sources: By the JCEMS Submission Declaration Form, all authors are required to disclose all potential conflicts of interest and funding sources. All authors declared that they have no conflicts of interest. All authors declared that they did not receive funding to conduct the research and/or writing associated with this work.

Authorship Criteria: By the JCEMS Submission Declaration Form, all authors are required to attest to meeting the four ICMJE.org authorship criteria: (1) Substantial contributions to the conception or design of the work; or the acquisition, analysis, or interpretation of data for the work; AND (2) Drafting the work or revising it critically for important intellectual content; AND (3) Final approval of the version to be published; AND (4) Agreement to be accountable for all aspects of the work in ensuring that questions related to the accuracy or integrity of any part of the work are appropriately investigated and resolved.

Prior Presentation: Preliminary data from this study were presented in abstract form at the at the Academic Poster Session of the 26th Annual Conference of the National Collegiate Emergency Medical Services Foundation; February 23, 2019; Pittsburgh, PA, USA.

Submission History: Received October 14, 2019; accepted for publication February 14, 2020.

Published Online: February 28, 2020

Published in Print: February 28, 2020 (Volume 3: Issue 1)

Reviewer Information: In accordance with JCEMS editorial policy, Original Research manuscripts undergo double-blind peer-review by at least two independent reviewers. JCEMS thanks the anonymous reviewers who contributed to the review of this work.

Copyright: () 2020 Chuck, Moseley, Kalagara \& Martin. This is an open access article distributed under the terms of the Creative Commons Attribution 4.0 International (CC BY 4.0) License, which permits unrestricted use, distribution, and reproduction in any medium, provided the original author and source are credited. The full license is available at: https://creativecommons.org/licenses/by/4.0/

Electronic Link: https://doi.org/10.30542/JCEMS.2020.03.01.04 


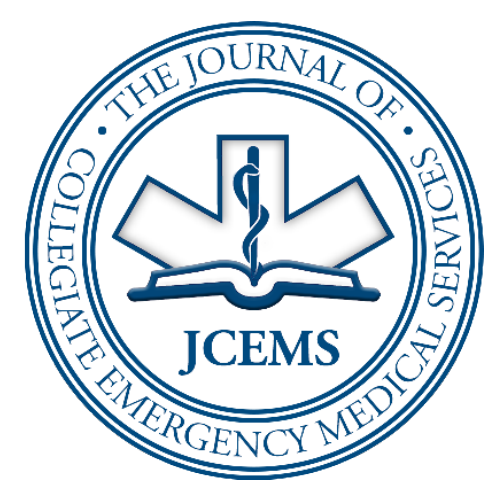

The Journal of

COLLEGIATE EMERGENCY MEDICAL SERVICES

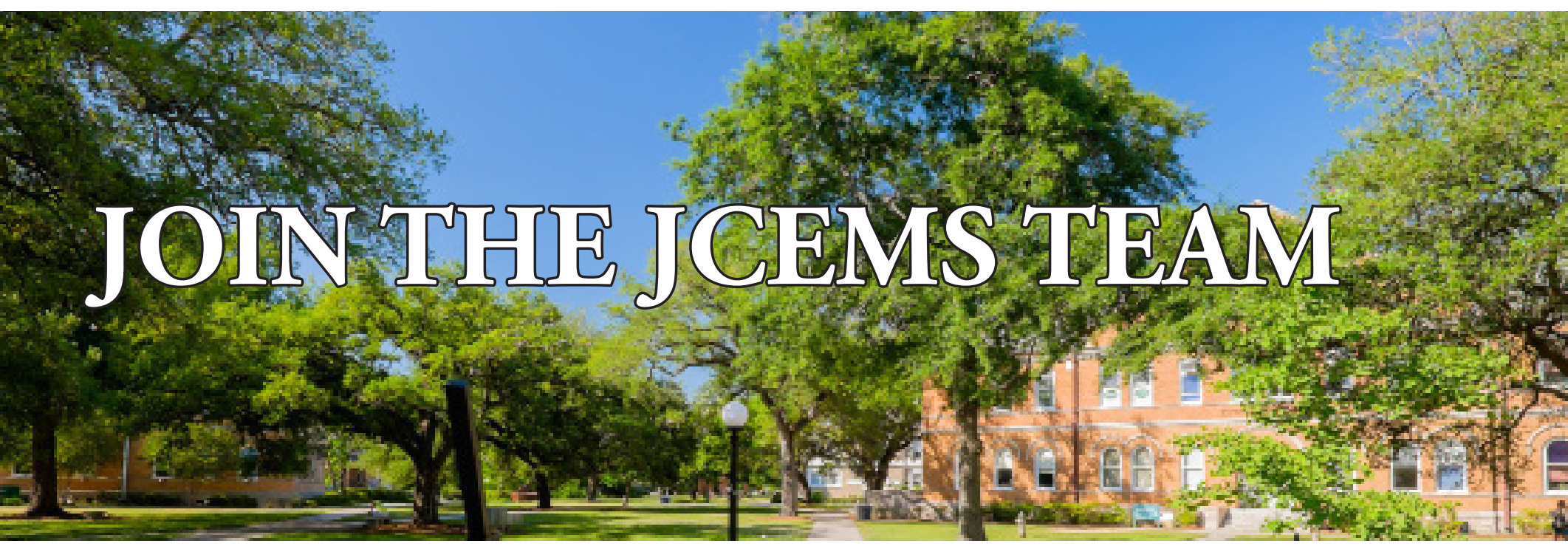

Now seeking motivated, passionate volunteers to join the JCEMS team. Available positions in the design, editing, outreach, and business management departments:

- Journalism \& Publishing

- $\quad$ Print \& Web Design

- $\quad$ Peer Review \& Copy-Editing

- Public Relations \& Social Media

- $\quad$ Advertising \& Marketing

Excellent opportunity for current students and recent alumni to gain professional leadership experience in an innovative, scholarly publication.

For open positions, please email JCEMS@collegeEMS.com or visit: https://www.collegeems.com/editorial-board/

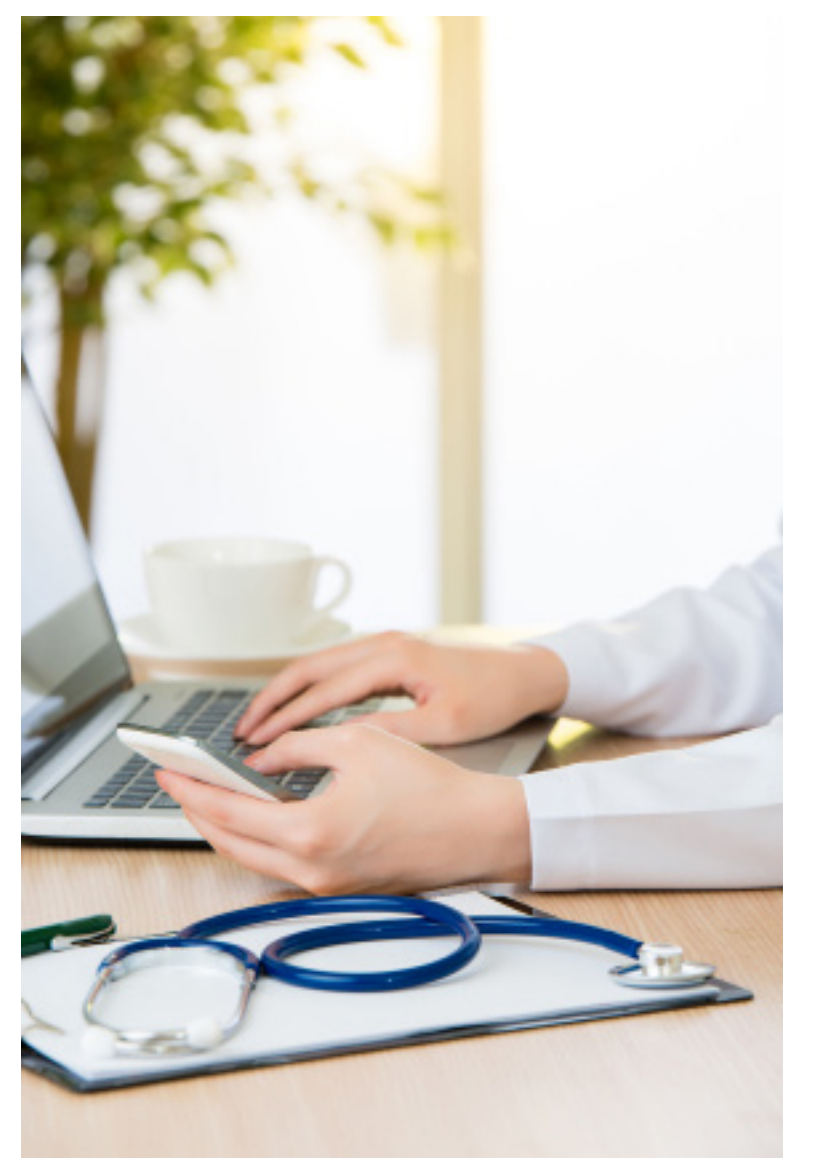




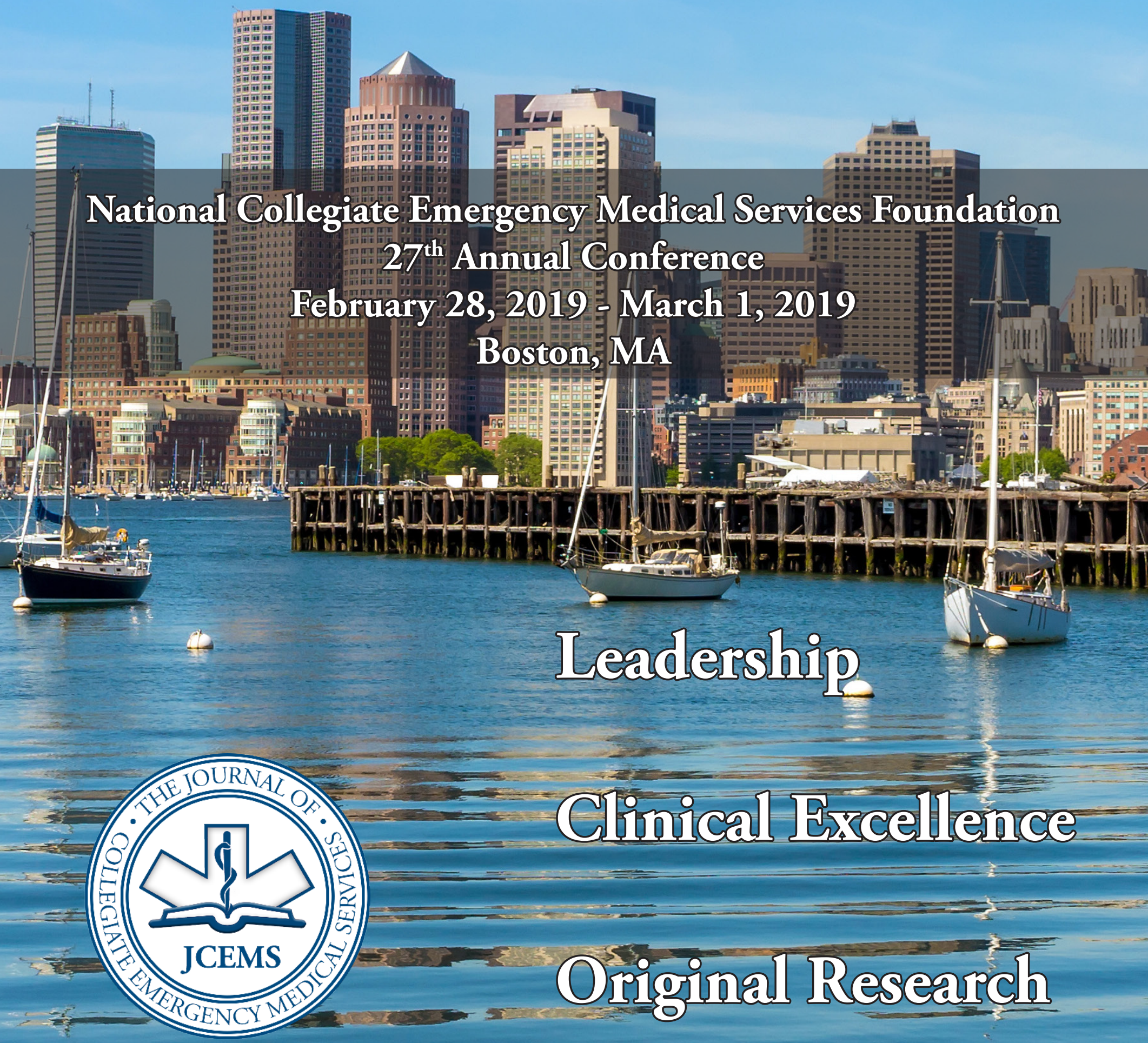

